\title{
A Mechanistic Account of Striatal Dopamine Function in Human Cognition: Psychopharmacological Studies With Cabergoline and Haloperidol
}

\author{
Michael J. Frank \\ University of Arizona
}

\author{
Randall C. O'Reilly \\ University of Colorado at Boulder
}

\begin{abstract}
The authors test a neurocomputational model of dopamine function in cognition by administering to healthy participants low doses of $\mathrm{D}_{2}$ agents cabergoline and haloperidol. The model suggests that DA dynamically modulates the balance of Go and No-Go basal ganglia pathways during cognitive learning and performance. Cabergoline impaired, while haloperidol enhanced, Go learning from positive reinforcement, consistent with presynaptic drug effects. Cabergoline also caused an overall bias toward Go responding, consistent with postsynaptic action. These same effects extended to working memory and attentional domains, supporting the idea that the basal ganglia/dopamine system modulates the updating of prefrontal representations. Drug effects interacted with baseline working memory span in all tasks. Taken together, the results support a unified account of the role of dopamine in modulating cognitive processes that depend on the basal ganglia.
\end{abstract}

Keywords: basal ganglia, dopamine, cognition, computational, psychopharmacology

The basal ganglia (BG) participate in various aspects of cognition and behavior by interacting with and modulating multiple areas of frontal cortex (Alexander, DeLong, \& Strick, 1986). Similarly, the neurotransmitter dopamine (DA) plays a modulatory role in cognition through extensive diffuse projections from midbrain DA nuclei to the BG and frontal cortical areas (Fallon \& Moore, 1978; Gerfen, 1992; Joel \& Weiner, 2000). Several neurological conditions implicate DA dysfunction, including Parkinson's disease, attention deficit/hyperactivity disorder (ADHD), and schizophrenia (Abi-Dargham et al., 2000; Dougherty et al., 1999; Ilgin et al., 2001; Kish, Shannak, \& Hornykiewicz, 1988; McGowan, Lawrence, Sales, Quested, \& Graby, 2004; Nieoullon, 2002; Seeman, 1987; Weiner \& Joel, 2002; Weinberger, 1987). Notably, the cognitive deficits observed in all of these conditions are qualitatively similar to those observed in patients with damage to prefrontal cortex (PFC; Barch et al., 2001; Brown \& Marsden, 1990; Cools, Barker, Sahakian, \& Robbins, 2001; Perlstein, Dixit,

Michael J. Frank, Department of Psychology and Program in Neuroscience, University of Arizona; and Randall C. O'Reilly, Department of Psychology and Center for Neuroscience, University of Colorado at Boulder. Additional materials are on the Web at http://dx.doi.org/10.1037/ 0735-7044.120.3.497.supp

This research was supported in part by General Clinical Research Center Grant M01RR00051 from the National Center for Research Resources of the National Institutes of Health (NIH), Office of Naval Research Grant N00014-03-1-0428, and NIH Grant MH069597-01. We thank the staff of the General Clinical Research Center at the University of Colorado at Boulder for their assistance and Karen Richardson for help in administering cognitive tasks to participants. We also thank Kent Hutchison and Tim Curran for helpful discussions.

Correspondence concerning this article should be addressed to Michael J. Frank, Department of Psychology and Program in Neuroscience, University of Arizona, 1503 East University Boulevard, Building 68, Tucson, AZ 85721. Email: mfrank@u.arizona.edu
Carter, Noll, \& Cohen, 2003; Willcutt et al., 2005). Consequently, the overwhelming tendency in the literature is to attribute patient cognitive deficits to dopaminergic dysfunction within PFC. This is a potentially valid attribution, given that selective disruption to prefrontal DA in monkeys gives rise to cognitive deficits that are similar to those observed under full excitotoxic PFC lesions (Sawaguchi \& Goldman-Rakic, 1991; Williams \& GoldmanRakic, 1995). However, there is growing evidence in both animals and humans that DA dysfunction within the BG alone can lead to frontal-like cognitive deficits (Collins, Wilkinson, Everitt, Robbins, \& Roberts, 2000; Crofts et al., 2001; Frank, 2005; J. O. Rinne et al., 2000).

Psychopharmacological studies that transiently manipulate the DA system in healthy individuals can potentially inform the cause of DA-related cognitive deficits. In particular, drugs that target the $\mathrm{D}_{2}$ receptor, which is predominantly expressed in $\mathrm{BG}$ relative to PFC (Camps, Cortes, Gueye, Probst, \& Palacios, 1989), can help determine the specific contributions of the BG. As such, $\mathrm{D}_{2}$ agents in humans have been shown to modulate striatal, but not prefrontal, blood flow (Honey et al., 2003; Mehta et al., 2003; see below for similar selectivity in animal studies). Previous studies with $\mathrm{D}_{2}$ agonists/antagonists in healthy participants have yielded mixed results, with findings of both cognitive enhancement and impairment associated with different doses, task conditions, and populations (Kimberg, D’Esposito, \& Farah, 1997; Luciana, Hanson, \& Whitley, 2004; Mehta, Manes, Magnolfi, Sahakian, \& Robbins, 2004; Mehta, Sahakian, McKenna, \& Robbins, 1999; Mehta, Swainson, Ogilvie, Sahakian, \& Robbins, 2001; Muller, von Cramon, \& Pollman, 1998; Peretti et al., 1997; Roesch-Ely et al., 2005). For example, Kimberg et al. (1997) and Gibbs and D'Esposito (2005) found that in tests of executive function, bromocriptine (a $\mathrm{D}_{2}$ agonist) enhanced performance in participants with low working memory span but impaired performance in those with high span (see also Mattay et al., 2000). This provocative result 
suggests that differences in working memory span are partially characterized by differences in baseline DA levels. However, the use of a $D_{2}$ agonist raises the question of whether these effects could be more indicative of DA processes within the BG rather than (or in addition to) PFC.

The present research attempts to clarify many of these complex issues, through the use of behavioral studies on a range of cognitive tasks in healthy participants administered two different $D_{2}$ agents with opposing effects (cabergoline, a $\mathrm{D}_{2}$ agonist, and haloperidol, a $\mathrm{D}_{2}$ antagonist). Cabergoline was chosen over bromocriptine because it has 7 times greater affinity for the $D_{2}$ receptor while still having low $\mathrm{D}_{1}$ affinity (Ichikawa \& Kojima, 2001), and has fewer negative side effects (Biller et al., 1996; Colao, Lombardi, \& Annunziato, 2000; Corsello et al., 2003; Stocchi et al., 2003; Webster, 1994). Similarly, haloperidol has superior in vivo $\mathrm{D}_{2}$ binding when compared with other agents (Kapur et al., 1996; Seeman \& Kapur, 2000) and has 25 times greater affinity for $D_{2}$ over $D_{1}$ (Bymaster et al., 1999). For additional drug and dose considerations, see supplementary materials posted on the Web at http://dx.doi.org/10.1037/ 0735-7044.120.3.497.supp

Our studies were designed to test specific predictions from existing biologically based computational models of DA modulation within the BG and the BG's modulatory role on frontal cortical function (Frank, 2005; Frank \& Claus, in press; Frank, Loughry, \& O'Reilly, 2001; O'Reilly \& Frank, 2006). As described in the next section, the model makes predictions about $\mathrm{D}_{2}$ drug effects on learning from positive and negative reinforcement in procedural learning tasks and on working memory updating in standard working memory tasks. These predictions were confirmed in our behavioral studies. Moreover, we found that the extent to which drug effects were observed depended on baseline working memory span, providing further support that individual differences in working memory ability may be determined in part by differences in the dopaminergic system, and specifically the $\mathrm{D}_{2}$ receptor system. Overall, these results provide support for a unified model of BG/DA function that holds across multiple cognitive processes, suggesting that the BG may play a more important role in cognitive function than is generally appreciated.

\section{A Mechanistic Account of Basal Ganglia Dopamine Function in Cognition}

An explicit, mechanistic framework for understanding the roles of the $\mathrm{BG}$ and $\mathrm{DA}$ in cognition has been developed through a series of neurocomputational models reported elsewhere (Frank, 2005, in press; Frank \& Claus, in press; Frank et al., 2001; O'Reilly \& Frank, 2006). These models build on other computational and theoretical work regarding the role of the BG in motor control (Beiser \& Houk, 1998; Brown, Bullock, \& Grossberg, 2004; Gurney, Prescott, \& Redgrave, 2001; Mink, 1996; Redgrave, Prescott, \& Gurney, 1999b), where many of the same neurobiological principles have been implemented in our models to explore their role in cognitive function. These models suggest that (a) the BG play a largely modulatory role in cognition and action, meaning that they do not directly implement any cognitive process but rather modulate function in cortical regions that do so; (b) DA dynamically modulates this already modulatory BG system; and (c) this DA modulation affects both the learning of new behaviors and the performance of already-learned behaviors. Furthermore, by virtue of interactions with different areas of frontal cortex (Alexander et al., 1986), the models show how the BG can participate in a wide range of cognitive functions, from relatively low-level tasks such as procedural/reinforcement learning (Frank, 2005; in press) to higher level tasks such as working memory (Frank et al., 2001; O’Reilly \& Frank, 2006) and decision making (Frank \& Claus, in press).

\section{Action Selection}

At the most general level, various models suggest that the BG modulate the selection of one of several action plans represented in frontal cortex (Brown et al., 2004; Frank, 2005; Frank et al., 2001; Gurney et al., 2001; Redgrave et al., 1999b). This action-selection framework leverages existing knowledge of BG involvement in motor control, in which the BG are thought to selectively facilitate a preferred motor command in premotor cortex while suppressing competing motor programs (Basso \& Wurtz, 2002; Hikosaka, 1994; Jiang, Stein, \& McHaffie, 2003; Mink, 1996). More specifically, two main projection pathways from the striatum go through different BG nuclei on the way to thalamus and up to cortex (see Figure 1). Activity in the direct pathway sends a Go signal to facilitate the execution of a response considered in cortex, whereas activity in the indirect pathway sends a No-Go signal to suppress competing responses. Further, by virtue of its diffuse projections to BG output nuclei (Parent \& Hazrati, 1995), the subthalamic nucleus may exert a global No-Go signal on the execution of all responses (Brown et al., 2004; Frank, in press), which can dynamically modulate the threshold for executing responses depending on the degree of response conflict present (Frank, in press). This model also showed that BG network dynamics during response selection are consistent with available physiological data in both intact and Parkinson states.

\section{Learning}

To investigate the roles of the BG/DA system in learning, the models also simulate transient changes in DA levels that occur during positive and negative reinforcement and their differential effects on the two BG pathways (Brown et al., 2004; Frank, 2005; Frank \& Claus, in press; O'Reilly \& Frank, 2006). In animals, phasic bursts of DA cell firing and release are observed during positive reinforcement - these are thought to act as teaching signals that lead to the learning of rewarding behaviors (Bayer \& Glimcher, 2005; Roitman, Philips, Stuber, Wightman, \& Careli, 2004; Schultz, 2002; Schultz, Dayan, \& Montague, 1997; Wickens, 1997). Conversely, choices that do not lead to reward are associated with DA dips (pauses in DA firing) that drop below baseline (e.g., Schultz, 2002; Satoh, Nakai, Sato, \& Kimura, 2003). Similar DA-dependent processes have been inferred to occur in humans during positive and negative reinforcement (Delgado, Nystrom, \& Fiez, 2000; Frank, Woroch, \& Curran, 2005; Holroyd \& Coles, 2002; Zald et al., 2004). Notably, DA is excitatory on synaptically driven Go activity via $\mathrm{D}_{1}$ receptors predominantly 
a)

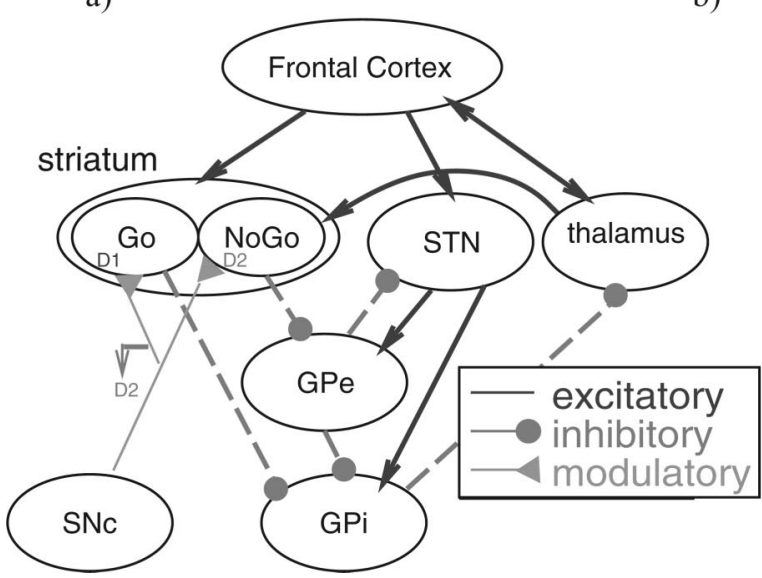

b)

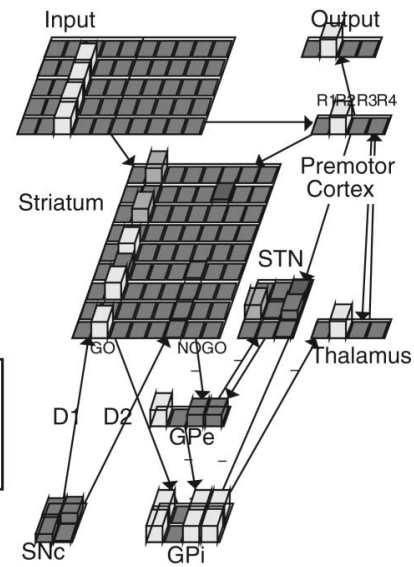

Figure 1. (a) The striato-cortical loops, including the direct ("Go") and indirect ("No-Go") pathways of the basal ganglia. The Go cells disinhibit the thalamus via the internal segment of globus pallidus (GPi), thereby facilitating the execution of an action represented in cortex. The No-Go cells have an opposing effect by increasing inhibition of the thalamus, suppressing actions from getting executed. Dopamine from the substantia nigra pars compacta (SNc) projects to the dorsal striatum, causing excitation of Go cells via $\mathrm{D}_{1}$ receptors and inhibition of No-Go via $\mathrm{D}_{2}$ receptors. $\mathrm{GPe}=$ external segment of globus pallidus; STN $=$ subthalamic nucleus. (b) The Frank (2005, in press) neural network model of this circuit (squares represent units, with height reflecting neural activity). The premotor cortex selects an output response via direct projections from the sensory input, and is modulated by the basal ganglia projections from the thalamus. Go units are in the left half of the striatum layer; No-Go units are in the right half of this region, with separate columns denoted for each of the four responses (R1 through R4). In the case shown, striatum Go is stronger than No-Go for R1, inhibiting GPi, disinhibiting thalamus, and facilitating R1 execution in cortex. A tonic level of dopamine is shown in SNc; a burst or dip ensues in a subsequent error feedback phase (not shown), driving Go/No-Go learning. The STN exerts a dynamic 'global No-Go' function on the execution of all responses, complementing the response-specific striatal No-Go cells (Frank, in press).

expressed in the direct pathway, ${ }^{1}$ whereas it is inhibitory on No-Go activity via $\mathrm{D}_{2}$ receptors predominantly expressed in the indirect pathway (Aubert, Ghorayeb, Normand, \& Bloch, 2000; Brown et al., 2004; Gerfen, 1992; Hernandez-Lopez, Bargas, Surmeier, Reyes, \& Galarraga, 1997; Hernandez-Lopez et al., 2000; Joel \& Weiner, 1999). In our models, positive reinforcement leads to increases in DA that enhance neural activity and synaptic plasticity via $D_{1}$ receptors in the Go pathway while decreasing activity and plasticity via $\mathrm{D}_{2}$ receptors in the No-Go pathway; this functionality is supported by various lines of neurobiological evidence (Centonze, Picconi, Gubellini, Bernardi, \& Calabresi, 2001; Frank, 2005; Mahon, Casassus, Mulle, \& Charpier, 2003; Mark, Soghomonian, \& Yamamoto, 2004; Nishi, Snyder, \& Greengard, 1997; Radnikow \& Misgeld, 1998). The net result is that increases in DA support Go learning to reinforce the good choice, whereas dips in DA have the opposite effect, supporting No-Go learning to avoid the bad choice (Brown et al., 2004; Frank, 2005; Joel \& Weiner, 1999; O'Reilly \& Frank, 2006). ${ }^{2}$ That is, low levels of DA during dips should release No-Go cells from their tonic $\mathrm{D}_{2}$ inhibition, allowing them to become more excited than their Go counterparts, driving learning in the opposite direction to DA bursts. Supporting this notion, $\mathrm{D}_{2}$ receptor blockade (simulating a lack of $\mathrm{D}_{2}$ stimulation during dips) is associated with enhanced No-Go (indirect pathway) activity and associated increases in corticostriatal longterm potentiation (Calabresi et al., 1997; Centonze et al., 2004; Finch, 1999; Robertson, Vincent, \& Fibiger, 1992), whereas $D_{2}$ stimulation inhibits No-Go activity (Black, Gado, \& Perlmutter, 1997) and decreases synaptic strength (Calabresi et al., 1997).
Moreover, we recently demonstrated strong support for a central prediction of the Frank (2005) model showing crossover interaction effects of DA medication on cognitive reinforcement learning

\footnotetext{
${ }^{1}$ A more accurate depiction is that DA may increase the signal-to-noise ratio via $D_{1}$ receptors in the direct pathway (Frank, 2005). That is, $D_{1}$ stimulation effects on striatal excitability depend on the membrane potential of the target cell, such that DA excites neurons with high membrane potentials (in the "up-state") while inhibiting those with low potentials (in the "down-state"; Hernandez-Lopez et al., 1997). As reviewed in Frank (2005), up-states are triggered by synaptically driven activity from cortex, and it is this activity that is further excited by DA. In contrast, down-state activity may represent biological noise or background signals that get suppressed by DA stimulation.

${ }^{2}$ Some have suggested that DA dips may not be functionally effective, as a result of already low baseline firing rates of DA cells, and that other neurotransmitters such as serotonin may be required for negative reinforcement learning (Bayer \& Glimcher, 2005; Daw, Kakade, \& Dayan, 2002) Whereas we do not discount a potential role for other neurotransmitters, we argue that the smaller range of DA dips (compared with bursts) is likely compensated for by the far greater sensitivity of $D_{2}$ (compared with $D_{1}$ ) receptors to low DA levels (Creese, Sibley, Hamblin, \& Leff, 1983; Goto \& Grace, 2005; Grace, 2001; Schultz, 1998). Thus, smaller DA dips would be sufficient to support No-Go learning via $\mathrm{D}_{2}$ receptors, whereas larger phasic bursts would be needed to support Go learning via $\mathrm{D}_{1}$ receptors. Given that DA decays from the striatal extracellular synapse with a half-life of $75 \mathrm{~ms}$ (Gonon, 1997), the critical information in DA dips for driving learning may be in the duration rather than in the magnitude of DA dips. Indeed, recent studies show that larger negative prediction errors are mirrored by longer duration pauses in DA firing, lasting up to $400 \mathrm{~ms}$ (Bayer, 2004).
} 
in Parkinson patients (Frank, Seeberger, \& O'Reilly, 2004). In a probabilistic learning task, all patients learned to make choices that were more likely to result in positive rather than negative reinforcement. The difference was that patients taking their regular dose of DA medication (L-dopa and DA agonists) implicitly learned more about the positive outcomes of their decisions (i.e., they were better at Go learning than No-Go learning), whereas those who had abstained from taking medication implicitly learned to avoid negative outcomes (better No-Go learning). Age-matched controls did not differ in their tendency to learn more from the positive/negative outcomes of their decisions. According to the model, low levels of available DA in Parkinson's disease made patients relatively insensitive to positive outcomes but allowed them to learn a No-Go response, to avoid choices leading to negative outcomes. ${ }^{3}$ DA medication reversed this bias and enhanced Go learning while concurrently impairing No-Go learning. The Go learning improvement can be explained by the increase in spike-dependent DA firing and release by L-dopa medication (Harden \& Grace, 1995; Pothos, Davila, \& Sulzer, 1998) and is consistent with beneficial medication effects on other tasks thought to depend on phasic DA bursts, such as cognitive sequence learning (Shohamy, Myers, Grossman, Sage, \& Gluck, 2005). No-Go learning deficits under DA medication are similarly predicted by the model, as DA medications (especially $\mathrm{D}_{2}$ agonists) would tonically stimulate $\mathrm{D}_{2}$ receptors and could effectively block the effects of DA dips needed to learn No-Go (Frank, 2005). This same effect was simulated in the model to explicitly account for selective reversal (i.e., No-Go) learning deficits in Parkinson's disease patients taking DA medication (Cools et al., 2001; Swainson et al., 2000) and can explain various other learning impairments in both humans and animals taking DA/ $\mathrm{D}_{2}$ medications, many of them directly related to No-Go learning situations (Bokura, Yamaguchi, \& Kobayashi, 2005; Charbonneau, Riopelle, \& Beninger, 1996; Cools, 2005; Cools, Barker, Sahakian, \& Robbins, 2003; Czernecki et al., 2002; Goto \& Grace, 2005; Mehta et al., 2001; Ridley, Haystead, \& Baker, 1981; Shohamy, Myers, Geghman, Sage, \& Gluck, in press; A. G. Smith et al., 1999). Cools, Lewis, Clark, Barker, and Robbins (2005) specifically showed that DA medication abolishes the normal ventral striatal No-Go activity observed when learning to suppress previously learned responses.

\section{Working Memory Updating}

In addition to these lower level reinforcement learning effects, we have shown that in parallel BG circuits, these same Go/No-Go mechanisms can also drive the updating of working memory representations in PFC (Frank et al., 2001; Frank, 2005; O'Reilly \& Frank, 2006; for related ideas see Beiser \& Houk, 1998; Bilder, Volavka, Lachman, \& Grace, 2004; Cools, 2005). Specifically, BG Go signals cause PFC to update and maintain current sensory information, whereas No-Go signals prevent updating, enabling robust ongoing maintenance of previously stored information. This function of the BG is consistent with striatal activation observed during working memory tasks (S. J. Lewis, Dove, Robbins, Barker, \& Owen, 2004) and with working memory/executive function deficits observed in various patient populations with a BG locus, such as Parkinson's disease and ADHD (Barch et al., 2001; Brown \& Marsden, 1990; Cools et al., 2001; Owen, Doyon, Dagher, Sadikot, \& Evans, 1998; Perlstein et al., 2003; Willcutt et al., 2005). Cools (2005) reviewed evidence that working memory deficits in Parkinson's disease are specific to the updating and manipulation of information (depending on the BG in our model), with relatively intact maintenance (subserved by their intact PFC). Further, Cools et al. (2001) showed that in Parkinson's disease patients, L-dopa administration improves task switching, which depends on updating of PFC representations and which would be facilitated by DA bursts and Go signals within the BG. This account can potentially explain the effects of $\mathrm{D}_{2}$ receptor agonists on working memory tasks (Kimberg et al., 1997; Mehta et al., 2003). Next, we outline the specific mechanisms by which we hypothesize these drugs to modulate cognitive function before describing the tasks designed to more specifically test these ideas.

\section{Model Predictions for $D_{2}$ Drugs: Pre- and Postsynaptic Effects}

To make predictions about how $\mathrm{D}_{2}$ drugs will affect performance in our model, we must take into account the two different isoforms of the receptor $\left(\mathrm{D}_{2}-\mathrm{S}\right.$ and $\left.\mathrm{D}_{2}-\mathrm{L}\right)$, expressed in pre- and postsynaptic neurons, respectively (Uziello et al., 2000). Whereas tonic DA signaling is affected by postsynaptic stimulation/blockade, phasic (transient) release of DA during dopaminergic cell bursting is modulated by presynaptic drug action (Grace, 1991). Although cognitive effects of $\mathrm{D}_{2}$ agents are often interpreted in terms of postsynaptic effects (e.g., agonists are thought to mimic the effects of DA, whereas antagonists block these effects), evidence from the animal literature suggests that low doses of these agents actually exert their effects primarily via presynaptic mechanisms (Richfield, Penney, \& Young, 1989; Schoemaker et al., 1997). Specifically, presynaptic $D_{2}$ autoreceptors tightly control the level of phasic DA release via inhibitory feedback (Grace, 1995; Schmitz, Benoit-Marand, Gonon, \& Sulzer, 2003; Starke, Gothert, \& Kilbinger, 1989). Thus, $\mathrm{D}_{2}$ agonists (e.g., cabergoline) stimulate autoreceptors and diminish the amount of phasic DA release, whereas typical $\mathrm{D}_{2}$ antagonists (haloperidol) actually increase DA bursting and release in the BG (but not PFC; Chen, Choi, Andersen, Rosen, \& Jenkins, 2005; Garris et al., 2003; Kuroki, Meltzer, \& Ichikawa, 1999; Moghaddam \& Bunney, 1990; Pehek, 1999; Westerink, 2002; Wu et al., 2002; see Figure 2). In other words, the effects of $\mathrm{D}_{2}$ agents on phasic DA release is exactly opposite to the pervasive assumptions of these effects in cognitive studies; this is critical for our predictions for drug effects on reinforcement learning processes, which depend on phasic DA bursts and dips during positive and negative feedback.

Nevertheless, to the extent that the drugs act on postsynaptic receptors, they should modulate overall (tonic) behavioral biases on $\mathrm{Go} / \mathrm{No}-\mathrm{Go}$ responding. As noted above, postsynaptic $\mathrm{D}_{2}$ receptors are predominantly expressed in the indirect/No-Go pathway (Gerfen, 1992), which acts to suppress the execution of cortical actions. Because DA is inhibitory to $\mathrm{D}_{2}$ receptors in the $\mathrm{BG}$ (Hernandez-Lopez et al., 2000), $\mathrm{D}_{2}$ agonists mimic this effect and inhibit No-Go neurons in the indirect pathway (Black et al., 1997)

\footnotetext{
${ }^{3}$ This preservation of No-Go learning may stem from the fact that even low tonic levels of DA are sufficient to stimulate high-affinity $\mathrm{D}_{2}$ receptors, and the $\mathrm{D}_{2}$ receptor supersensitivity in Parkinson's disease (Ichise et al., 1999; U. K. Rinne et al., 1990; Zhen, Torres, Cai, \& Friedman, 2002) would make these receptors particularly sensitive to DA dips.
} 
a)

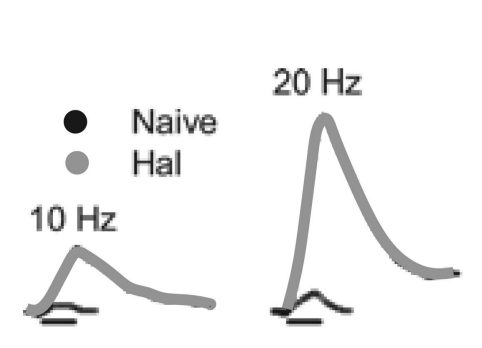

b)

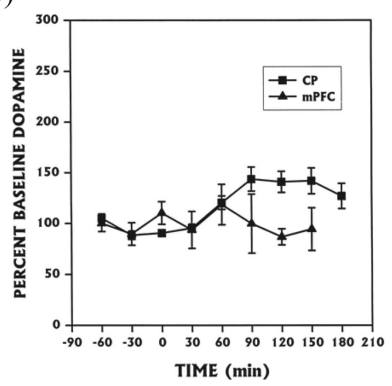

Figure 2. (a) Haloperidol (Hal) administration vastly increases spikedependent DA release in the striatum upon external DA cell stimulation, an effect that is most significant at stimulation frequencies that are characteristic of bursting, as is observed during delivery of unexpected reward. From "Concurrent Autoreceptor-Mediated Control of Dopamine Release and Uptake During Neurotransmission: An In Vivo Voltammetric Study" by Q. Wu, M. E. Reith, Q. D. Walker, C. M. Kuhn, F. I. Carroll, \& P. A. Garris, 2002, Journal of Neuroscience, 22, p. 6275. Copyright 2002 by the Society for Neuroscience. Reprinted with permission. (b) Acute, systemic haloperidol administration increases dopamine release in the striatum (caudate-putamen $[\mathrm{CP}]$ ) but not in the medial prefrontal cortex (mPFC). From "Comparison of Effects of Haloperidol Administration on Amphetamine-Stimulated Dopamine Release in the Rat Medial Prefrontal Cortex and Dorsal Striatum" by E. A. Pehek, 1999, Journal of Pharmacology and Experimental Therapeutics, 289, p. 16. Copyright 1999 by the American Society for Pharmacology and Experimental Therapeutics. Reprinted with permission. Similar selective effects have been reported elsewhere for acute, but not chronic, administration.

and should thereby have a net facilitatory effect on the execution of cortical actions. In other words, they should lower the threshold for facilitating responses and speed up reaction times. In contrast, $\mathrm{D}_{2}$ antagonists should have the opposite effect, disinhibiting the No-Go/indirect pathway, raising the response threshold, and slowing reaction times. This is consistent with the general tendency for DA and its agonists to increase locomotive behavior, whereas chronic DA blockade leads to catalepsy and Parkinsonism (Fog, 1972).

Thus, taking both pre- and postsynaptic mechanisms into account (see Table 1), cabergoline should result in more overall Go responding (via postsynaptic stimulation) but less learning of the positive consequences of a given response (via presynaptic reduction of phasic DA release). In contrast, haloperidol should theoretically enhance No-Go signals (raising the threshold for action and therefore less Go responding) but also enhance DA bursting (thereby enhancing learning of positive outcomes of responses). However, due to constraints on safety and risk management, we chose a low dose of haloperidol $(2 \mathrm{mg})$ that is unlikely to have significant postsynaptic effects: Although having high affinity for presynaptic autoreceptors, haloperidol only activates postsynaptic receptors at higher doses and/or chronic administration (Schoemaker et al., 1997), at which point catalepsy and Parkinsonism is induced by postsynaptic $\mathrm{D}_{2}$ blockade (Sanberg, 1980). ${ }^{4}$ Indeed, unlike patients taking higher doses of the drug (Kumari et al.,1997), participants in our study and other low-dose $\mathrm{D}_{2}$ antagonist studies did not have Parkinson-like slowness of reaction times (Mehta et al., 1999, 2004; Peretti et al., 1997). Thus, we predict that the haloperidol effects will hinge on presynaptically mediated enhancement of DA bursting, supporting increased Go learning.
Because of these contrasting drug effects on pre- and postsynaptic $\mathrm{D}_{2}$ receptors, our framework also provides an interesting interpretation of opposite cognitive drug effects that have been found in participants with low and high working memory span (e.g., Gibbs \& D'Esposito, 2005; Kimberg et al., 1997). Specifically, as was proposed by Kimberg et al. (1997), low- and highspan participants may differ in their underlying dopaminergic systems and therefore may respond differentially to the drugs. Indeed, in our study we found that low-span participants consistently showed greater overall drug effects than high-span participants for both drugs, across motor, learning, working memory, and low-level biological marker data. We propose that these differences may depend on the extent to which drugs act on pre- versus postsynaptic $\mathrm{D}_{2}$ receptors. When both the overall drug effects and these working memory span effects are taken into account, we expect a range of pre- and postsynaptic effects across groups, as discussed below and motivated by observed biological drug effects (see Figure 3).

\section{Empirical Tests of Unified BG/DA Model}

\section{General Method}

We tested 28 healthy participants ( 15 women, 13 men) between the ages of 18 and 35 years $(M=21, S E M=0.75)$. We conducted three behavioral experiments to test the predictions from our model: probabilistic selection (two alternative forced-choice), probabilistic Go/No-Go learning and reversal, and modified versions of the widely used AX continuous performance task (AX-CPT) of working memory, including attentional-shifting and reversal conditions. The probabilistic selection task was used in previous work to test our model predictions with respect to individual differences in learning from positive versus negative reinforcement in both Parkinson patients (Frank et al., 2004) and electrophysiological correlates in healthy participants (Frank et al., 2005). The probabilistic Go/No-Go paradigm allows more direct assessment of the Go/No-Go processes that we ascribe to the BG. The AX-CPT working memory task (Barch et al., 1997; Barch et al., 2001; Servan-Schreiber, Cohen, \& Steingard, 1997) supports the analysis of multiple components of executive function and is critical for determining whether the same Go/No-Go processes at work in the simpler procedural learning tasks also apply to working memory updating and attentional effects, as predicted by our model. We describe each of these tasks below; additional procedural details are included in the supplemental materials document posted on the Web at http://dx.doi.org/10.1037/0735-7044.120.3.497.supp.

We also measured participant's working memory span using the standard reading span task (Daneman \& Carpenter, 1980) to determine whether DA drug effects interacted with baseline working memory span as in previous studies (Gibbs \& D’Esposito, 2005; Kimberg et al., 1997). Participants were categorized as low or high span according to a median-split on this measure. Each participant was tested on all tasks in three different drug conditions (with the order counterbalanced): (a) cabergoline $\left(\mathrm{D}_{2}\right.$ agonist), $1.25 \mathrm{mg}$, (b) haloperidol ( $\mathrm{D}_{2}$ antagonist), $2 \mathrm{mg}$, and (c) a placebo. We measured serum prolactin levels to determine the degree to which the DA drugs had biologically measurable effects. We begin with the prolactin results, as they constrain our interpretation of the subsequent behavioral results, described thereafter. As summarized earlier, we found that the $\mathrm{D}_{2}$

\footnotetext{
${ }^{4}$ Consistent with this, $\mathrm{D}_{2}$ blockade reduced behavioral responding during acquisition of an appetitive response, but actually resulted in enhanced conditioned responding in a subsequent test conducted after drug washout (Eyny \& Horvitz, 2003); that is, the drug had a No-Go performance effect during acquisition but resulted in enhanced Go learning that was only evident once this performance effect wore off.
} 
Table 1

Summary of Hypothesized Effects of $D_{2}$ Agonists (e.g., Cabergoline) and Antagonists (e.g., Haloperidol) on Presynaptic (pre) and Postsynaptic (post) Receptors

\begin{tabular}{|c|c|c|c|c|c|c|}
\hline \multirow[b]{2}{*}{$\mathrm{D}_{2}$ receptor } & \multirow{2}{*}{$\begin{array}{l}\text { Stimulate } \\
\text { or block }\end{array}$} & \multirow[b]{2}{*}{ Drug } & \multicolumn{4}{|c|}{ Effects } \\
\hline & & & Biological & Motor & Learning & WM updating \\
\hline \multirow[t]{2}{*}{ Post (tonic) } & Stimulate & Cabergoline & $\downarrow$ No-go, $\uparrow$ Go & Faster RT & - & $\uparrow$ Go (distractible) \\
\hline & Block & Haloperidol & $\uparrow$ No-go, $\downarrow$ Go & Slower RT & - & $\downarrow$ Go (forgetful) \\
\hline \multirow[t]{2}{*}{ Pre (phasic) } & Stimulate & Cabergoline & $\downarrow$ DA bursts & - & $\downarrow$ Go (pos fdbk) & $\downarrow$ Go (task-relevant) \\
\hline & Block & Haloperidol & $\uparrow$ DA bursts & - & $\uparrow$ Go (pos fdbk) & $\uparrow$ Go (task-relevant) \\
\hline
\end{tabular}

Note. Postsynaptic $\mathrm{D}_{2}$ receptors are predominantly on the No-Go (indirect pathway neurons), where they are inhibitory. Presynaptic autoreceptors affect dopamine (DA) phasic bursts via inhibitory feedback, such that stimulation of these receptors reduces DA bursting. RT $=$ reaction time; pos fdbk $=$ learning from positive feedback (which activates the Go pathway via DA bursts). Excessive working memory (WM) updating caused by excessive basal ganglia Go signals can lead to increased distractibility, whereas suppressed updating can lead to lack of encoding of information (forgetfulness). Note that the $\mathrm{D}_{2}$ receptor types have differential sensitivity, with presynaptic receptors more sensitive to acute drug doses than postsynaptic ones. As explained in the text, we did not expect significant haloperidol postsynaptic effects (see also Figure 3 ).

drug effects as measured by prolactin (and corroborated by consistent patterns of behavioral data across all tasks) were stronger for cabergoline than for haloperidol and stronger in low working memory span participants than in those with high span working memory.

Serum prolactin levels provide an indirect measure of $\mathrm{D}_{2}$ agent effects, because $D_{2}$ receptor stimulation inhibits the secretion of this hormone in the pituitary (Ben-Jonathan, 1985). Prolactin levels were obtained before drug ingestion and $4 \mathrm{hr}$ later, after cognitive tests. There was a main effect of drug on prolactin levels, $F(2,25)=21.7, p<.0001$, such that both drugs effectively modulated prolactin secretion in opposite directions. Although placebo was associated with diminished prolactin levels over this 4-hr period (prolactin levels normally decrease during the day), cabergoline significantly decreased prolactin secretion beyond that observed under placebo, $F(1,25)=40.6, p<.0001$. In contrast, haloperidol resulted in

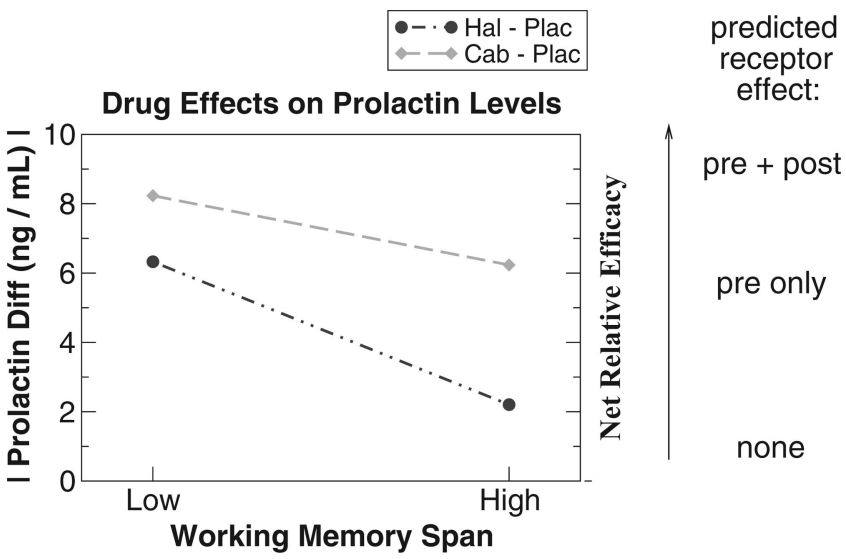

Figure 3. Absolute values of drug effects on serum levels of the hormone prolactin (in actuality cabergoline [Cab] reduced prolactin levels). Drug effects on prolactin depended on baseline working memory span, consistent with putative differences in dopaminergic function across span groups. Haloperidol (Hal) significantly increased prolactin levels only in low-span participants. Cabergoline decreased prolactin levels in both span groups, but to a greater extent in low-span participants. These biological results lead to differential predictions regarding pre- and postsynaptic drug effects on cognition in the two span groups. Because presynaptic $\mathrm{D}_{2}$ receptors are more sensitive than postsynaptic receptors, we hypothesized that haloperidol would exert only presynaptic effects and only in low-span participants. Cabergoline was expected to exert presynaptic effects in both span groups, with additional postsynaptic effects only in low-span participants. Diff $=$ difference. increased prolactin levels, which was significant relative to placebo, $F(1$, $25)=7.9, p=.0096$. For cabergoline, both low-span, $F(1,25)=26.3, p<$ .0001 and high-span, $F(1,25)=15.3, p=.0006$ participants showed significant drug effects relative to placebo. Nevertheless, this effect was numerically larger in low-span participants. This is further corroborated by a marginal negative correlation between prolactin levels under cabergoline and the number of errors made in the working memory span test $(r=$ $-0.38, p=.08)$. Span effects were even more apparent under haloperidol: Only the low-span participants showed significant drug effects relative to placebo, $F(1,25)=10.6, p=.0032$, whereas high-span participants did not, $F(1,25)=0.53$. Notably, the mechanism by which haloperidol increases prolactin levels has been shown to operate via short-isoform $\mathrm{D}_{2}$ receptors (Nilsson, Ekman, Hellstrand, \& Eriksson, 1996), which is the same isoform that is seen in presynaptic autoreceptors in the BG (Uziello et al., 2000). Thus the degree to which haloperidol increases prolactin can be taken as an indirect measure of the degree to which it increases DA levels via presynaptic mechanisms.

On the basis of these results and their theoretical correspondence to the effects on pre- and postsynaptic $\mathrm{D}_{2}$ receptors (shown on the right of Figure 3 ), we included working memory span as a variable in all the behavioral analyses described below, including those tasks not involving working memory per se. We expect model predictions to hold in general across all participants, but additional effects of baseline working memory span can lead to differential behavior in particular conditions. Specifically, low-span participants under haloperidol should show the greatest evidence for enhanced DA bursts, whereas high-span participants-who were not affected by haloperidol in terms of prolactin-may not show any statistically significant effects on cognitive measures. Under cabergoline, high-span participants should show selective evidence for reduction of DA bursts on account of predominate activation of sensitive presynaptic $D_{2}$ receptors. Low span participants under cabergoline, who exhibited increased drug efficacy on prolactin, may also have tonic postsynaptic $\mathrm{D}_{2}$ stimulation, in addition to presynaptic effects. According to the model, this would cause an overall Go response bias (e.g., a lowered response threshold and more overall working memory updating) and could counteract presynaptic effects. These predictions from our modeling framework are consistent with the results reported below across a range of measures.

\section{Cognitive Task I. Probabilistic Selection, Two-Alternative Forced-Choice}

\section{Procedure}

In the Probabilistic Selection task (Frank et al., 2004, 2005), three different stimulus pairs $(\mathrm{AB}, \mathrm{CD}, \mathrm{EF})$ are presented in random order, and participants must learn to choose one of the two stimuli (see Figure 4). 
Feedback follows the choice to indicate whether it was correct or incorrect, but this feedback is probabilistic. In AB trials, a choice of stimulus A leads to correct (positive) feedback in $80 \%$ of $\mathrm{AB}$ trials, whereas a $\mathrm{B}$ choice leads to incorrect (negative) feedback in these trials (and vice versa for the remaining 20\% of trials). $\mathrm{CD}$ and $\mathrm{EF}$ pairs are less reliable: Stimulus $\mathrm{C}$ is correct in $70 \%$ of $\mathrm{CD}$ trials, whereas stimulus $\mathrm{E}$ is correct in $60 \%$ of $\mathrm{EF}$ trials. Over the course of training, participants learn to choose stimuli A, C, and $\mathrm{E}$ more often than $\mathrm{B}, \mathrm{D}$, or F. Note that learning to choose A over B could be accomplished either by learning that A leads to positive feedback or that B leads to negative feedback (or both). To evaluate whether participants learned more about positive or negative outcomes of their decisions, we subsequently tested them with novel combinations of stimulus pairs involving either an $\mathrm{A}(\mathrm{AC}, \mathrm{AD}, \mathrm{AE}, \mathrm{AF})$ or a $\mathrm{B}(\mathrm{BC}, \mathrm{BD}, \mathrm{BE}$, $\mathrm{BF}$ ); no feedback was provided. If participants learned more from positive feedback, they should reliably choose stimulus A in all novel test pairs in which it is present. On the other hand, if they learned more from negative feedback, they should more reliably avoid stimulus B.

We hypothesized that when taking haloperidol, participants would learn more about Go and less about No-Go responses, because of the enhancement of phasic DA bursts (via presynaptic $\mathrm{D}_{2}$ receptor blockade) during positive feedback. In contrast, we predicted that cabergoline would yield the opposite effect, impairing Go learning from positive feedback as a result of reduced DA bursts. These effects should be particularly evident in low-span participants under haloperidol and high-span participants under cabergoline. Finally, postsynaptic effects of cabergoline in low-span participants should be associated with an overall Go response bias, which should translate into speeded (decreased) reaction times.

\section{Results and Discussion}

Both drugs displayed the predicted effects on the novel test pair generalizations (Figure $4 \mathrm{~b}$ ). We filtered out participants who did not perform above $50 \%$ on the most trivial training pair (AB) during the test; their test results are meaningless if they could not reliably choose A and avoid B in this pair (Frank et al., 2004, 2005). There was a crossover interaction between the effects of cabergoline and haloperidol on positive/negative feedback learning, $F(1,24)=22.7, p<.0001$. Specifically, compared with placebo, haloperidol ingestion was associated with an increased tendency to choose the most positive stimulus (i.e., A) and a decreased tendency to avoid the most negative stimulus (B) in the novel test pairs, $F(1,24)=14.0, p=.001$. Cabergoline had the opposite effect, making participants better at avoiding $\mathrm{B}$ than choosing A, $F(1,24)=7.0, p=.014$. These differences in Go/No-Go learning under cabergoline and haloperidol are strikingly similar to the pattern observed in PD patients on and off medication in the same task (Frank et al., 2004; Figure 4c), and support the notion that (a) under cabergoline, decreased DA release during positive feedback impaired Go learning for good choices and (b) under haloperidol, increased DA release during positive feedback enhanced Go learning for good choices. Finally, these differences in learning biases on the drugs were found despite no overall learning bias in this task (main effect of positive/ negative test condition), $F(1,24)=1.1, n s$, and no main effect of a)

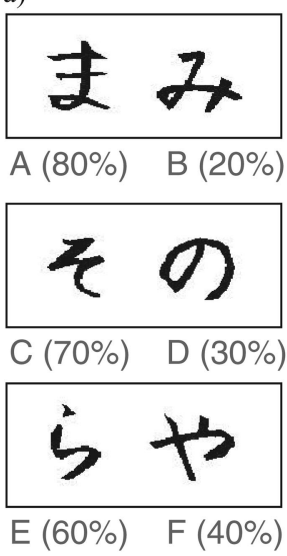

b)

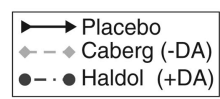

Probabilistic Selection

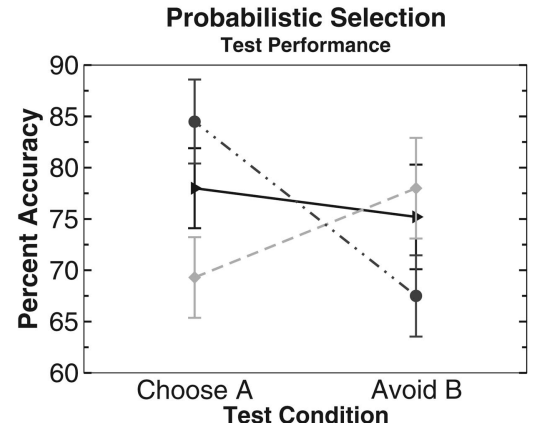

c)

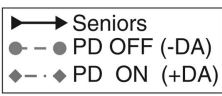

Probabilistic Selection Test Performance

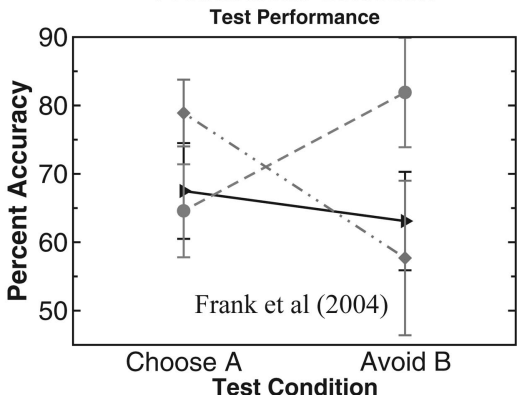

Figure 4. Probabilistic selection task and results. (a) Example stimulus pairs (Japanese Hiragana characters), which minimize explicit verbal encoding. Each pair is presented separately in different trials, with participants pressing a key to select the stimulus on the left or another key to select the stimulus on the right. Three different pairs are presented in random order; correct choices are determined probabilistically. Note that in actuality the position of the correct stimulus was randomized across trials, and the assignment of Hiragana characters to hierarchical element was randomized across participants. Different Hiragana characters were used in each session, so these were always novel. (b) Results from healthy participants taking cabergoline (Caberg) and haloperidol (Haldol; present study). There was a crossover interaction between medication condition and tendency to learn from positive versus negative feedback. Participants on placebo learned equally as much about the positive consequences of choosing Stimulus A and the negative consequences of choosing Stimulus B. Haloperidol enhanced positive feedback learning overall, causing a corresponding decrease in avoidance of Stimulus B, which was associated with positive feedback on a minority of trials. Cabergoline impaired positive feedback learning. See Figure 9c for additional effects of working memory span. (c) These drug results mirror those found previously in patients with Parkinson's disease (PD) on and off dopaminergic (DA) medication. Error bars represent standard error of the mean. From "By Carrot or by Stick: Cognitive Reinforcement Learning in Parkinsonism” by M. J. Frank, L. C. Seeberger, \& R. C. O’Reilly, 2004, Science, 306, p. 1941. Copyright 2004 by the American Association for the Advancement of Science. Reprinted with permission. 
drug on overall accuracy during test, $F(2,24)=0.4$. Similarly, there was no effect of drug on overall accuracy during training, $F(2,24)=1.5, n s$, or on the number of training trials required to reach criterion before advancing to test, $F(2,24)=1.6, n s$.

Notably, the extent to which the drugs modulated learning biases depended on the participant's baseline working memory span, $F(2,24)=4.5, p=.02$ (Figure 9c, presented later), consistent with the effects depicted in Figure 3. In particular, haloperidol significantly enhanced learning from positive relative to negative reinforcement in low-span participants, $F(1,24)=16.6, p=$ .0004 , whereas this effect was absent in high-span participants, $F(1,24)=0.53$. The opposite effect of cabergoline in impairing positive feedback learning was significant in high-span participants, $F(1,24)=13.9, p=.001$ but not in low-span participants, $F(1,24)=0.1$. These span-dependent drug effects were found despite the absence of a main effect of working memory span, $F(1$, $24)=2.1, n s$, and the lack of an interaction between span and positive/negative test condition, $F(1,24)=0.0$. Thus, although working memory span is not a critical factor in overall positive versus negative reinforcement learning, a span effect was revealed by our drug manipulations. Thus, these results are consistent with the notion that individual differences in working memory span are partially characterized by underlying differences in dopaminergic function.

A further prediction of this account is that only low-span participants receiving cabergoline should display evidence of postsynaptic $\mathrm{D}_{2}$ receptor stimulation and therefore have a Go bias, which would be manifest by decreased (speeded) RTs (see Table 1 and Figure 3). We restricted our analysis to the first 10 trials of the training session, in order to disentangle possible effects due to learning. Reaction times (RTs) were log transformed (to normalize the distribution). We found that cabergoline sped up RTs across all participants compared with placebo, $F(1,26)=6.8, p=.015$, but that this effect was only reliably observed in low-span participants receiving cabergoline, $F(1,26)=4.1, p=.05$, and not high-span participants in this condition, $F(1,26)=2.8$, ns. These results are also consistent with recent observations showing speeded reaction times by bromocriptine ( $\mathrm{D}_{2}$ agonist) only in low-span participants (Gibbs \& D'Esposito, 2005). For haloperidol, rather than slowing RTs as would be predicted by postsynaptic blockade, the drug actually sped up RTs, $F(1,26)=8.0, p=.009$. This result is consistent with the hypothesis that the low dose had selective presynaptic effects and increased DA release, leading to faster RTs. Once again, this effect was reliably observed in low-span participants, $F(1,26)=9.0, p=.006$ but not in high-span participants, $F(1,26)=1.0$, ns. Thus, in addition to predictably modulating reinforcement learning biases, the drug and span effects were consistent with specific predictions of our account even at the level of RTs.

\section{Cognitive Task II: Probabilistic Go/No-Go and Reversal}

\section{Procedure}

The second task involved a probabilistic reinforcement Go/No-Go paradigm, in which stimuli were presented one at a time, and the participant was to either press a key (Go) or withhold his or her response (No-Go). They were told that some stimulus patterns would give them a point if selected, whereas others would cause them to lose a point, and they were to try to maximize point totals. After Go responses, visual feedback was provided ("You won a point!" written in blue, or "You lost a point" written in red). Six different patterns were presented in random order, associated with reinforcement probabilities of $80 \%, 70 \%, 60 \%, 40 \%, 30 \%$ and $20 \%$ (see Figure 5). In completing this task, participants learn over time that three of the stimuli should be associated with a button press (because their corresponding probabilities of reinforcement are greater than 50\%) but that responses made to the other three will likely cause them to lose points. A test session followed the training block, in which the training stimuli and novel combinations of these stimuli were presented without feedback. In novel combinations, the left and right halves of the combined pattern each represent one of the training patterns. For example, half of the composite pattern may consist of a familiar pattern that is $80 \%$ correct, whereas the other half consists of one that is $80 \%$ incorrect, so that the combined pattern should be equally associated with Go and No-Go responses. In some cases one of the patterns is more strongly associated (i.e., $80 \%$ combined with $60 \%$ ), but in others the associations are equal (80/80). Following this test session, a second training block ensued in which the probabilities of reinforcement to the different patterns were reversed. Participants must learn to respond to stimuli that were previously incorrect and stop responding to stimuli that were previously correct.

We hypothesized that under haloperidol, with enhanced DA bursting during positive feedback, participants should learn more about Go than about No-Go and will therefore tend to respond Go to the combined pattern. Again, this effect should be particularly evident for participants receiving haloperidol. Conversely, cabergoline, with decreased DA bursting, should result in the opposite pattern in high-span participants. This is exactly the same predicted pattern as in the prior probabilistic selection task, for the same reasons. However, we also expected to observe effects of postsynaptic $\mathrm{D}_{2}$ stimulation in low-span participants receiving cabergoline, resulting in an overall Go response bias that would cause more overall responding and therefore mask (or counteract) any Go learning deficit.

\section{Results and Discussion}

The primary results of interest are the test phase responses to novel stimulus pairs (see Figure 6). As predicted, there was a crossover interaction between the effects of cabergoline and haloperidol on Go/No-Go learning, $F(1,26)=4.4, p=.046$, where Go learning is assessed by accuracy when the most positive stimulus is present and No-Go learning is assessed by accuracy in withholding responses to the most negative stimulus. Haloperidol was associated with increased Go learning and decreased No-Go learning relative to placebo, $F(1,26)=5.1, p=.03$. This effect was reliable in low-span participants, $F(1,26)=7.4, p=.01$ but not in high-span participants, $F(1,26)=0.4$. Cabergoline was associated with less Go responding to the most positive stimulus (i.e., impaired Go learning) in high-span participants, $F(1,26)=$ $5.9, p=.02$, but not in low-span participants, $F(1,26)=0.02$. This result is consistent with the notion that in low-span participants, tonic postsynaptic $\mathrm{D}_{2}$ stimulation caused an overall Go bias that counteracted any Go learning deficit arising from reduced DA bursts during positive feedback. This Go bias in low-span participants is further evidenced by their deficit in withholding responses to negative stimuli, $F(1,26)=10.3, p=.003$. In contrast, in high-span participants, we suggest that a pure presynaptic reduction of DA bursts resulted in impaired Go learning. The results from the training pairs showed exactly the same pattern, although effects were not as reliable (particularly for cabergoline), likely because of the participants' abilities in explicitly "memorizing" the correct responses to each training pattern. Finally, in evenly matched novel pairs (e.g., an $80 \%$ Go response paired with an $80 \%$ No-Go response), haloperidol was associated with more Go responding, in comparison with cabergoline, to the composite stimulus, $F(1,26)=4.5, p=.04$. In short, these results replicate and 
Train:

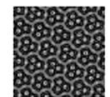

A. $(80 \%)$

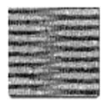

B $(70 \%)$

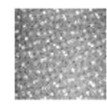

C $(60 \%)$

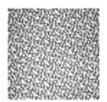

D (40\%)

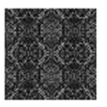

$E(30 \%)$

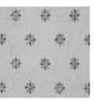

F $(20 \%)$

\section{Test (pos):}
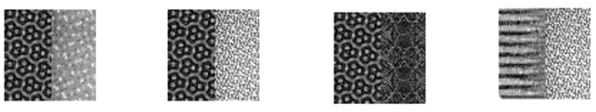

AC

$\mathrm{AD}$

$\mathrm{AE}$

$\mathrm{BD}$

\section{Test (neg):}
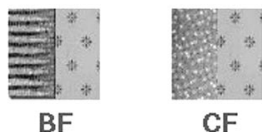

CF

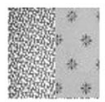

DF

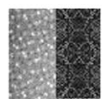

$\mathrm{CE}$

\section{Test (equal):}
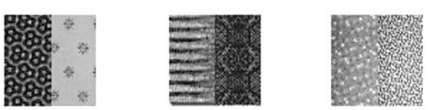

AF

$\mathrm{BE}$

$\mathrm{CD}$

Figure 5. Example stimuli for the probabilistic Go/No-Go task. Each training stimulus is presented alone in separate trials. Participants are instructed to respond either "Go" (by pressing the spacebar) or "No-Go" (by withholding their response). After Go responses, feedback is presented with probabilistic reinforcement; percentage of positive reinforcement (pos) is indicated in parentheses. Half of the stimuli are associated with greater probability of positive reinforcement, whereas the other half are more likely to result in negative reinforcement (neg). During the test phase, training stimuli are represented interleaved with novel composites of two training stimuli. In the test (pos) pairs, the combined value of the composite stimulus is positive. In the test (neg) pairs, the combined value of the composite stimulus is negative. In the test (equal) pairs, the combined value of the composite stimulus is neutral (i.e., the individual stimulus elements are equally associated with Go and No-Go responses). Note that in actuality the left and right positions of the stimuli were randomized across trials, and the assignment of texture pattern to frequency of positive feedback was randomized across participants. Different patterns were used in each session, so these were always novel.

extend those from the probabilistic selection task, in accord with model predictions.

\section{Reversal}

Reversal learning challenges both Go and No-Go learning: Go learning is required for overcoming the previously negatively reinforced stimuli, and No-Go learning is needed to avoid responding to previously positively reinforced stimuli. A Go learning deficit was evident relative to placebo in the high-span group receiving cabergoline in terms of less Go responding for the most positive stimulus, $F(1,26)=6.7, p=.015$, with no effect for the low-span group receiving cabergoline group, $F(1,26)=1.0, n s$. This is again consistent with the Go learning deficit in high-span participants, which is counteracted by a tonic Go bias in those with low-span working memory. For the haloperidol group, we hypothesized that participants would have difficulty withholding their responses (No-Go) to previously positive stimuli, on account of increased DA bursts in the initial segment. However, as it turned out, all participants (including those under placebo) were rather unsuccessful in learning No-Go, as evidenced by their overwhelming tendency to perform much worse at withholding this response compared with learning to respond Go to previously negative stimuli, $F(1,26)=35.4, p<.0001$. Nevertheless, low-span participants under haloperidol were numerically, but not significantly, worse at No-Go reversal learning, $F(1,26)=0.3$.

\section{Summary: Cognitive Procedural Learning}

Across both procedural/reinforcement learning tasks, haloperidol was associated with better Go learning from positive feedback versus No-Go learning from negative feedback, particularly in low working memory span participants. Conversely, cabergoline was associated with the opposite pattern in high-span participants. These results are consistent with our predictions for increased versus decreased DA bursting resulting from presynaptic $\mathrm{D}_{2}$ receptor blockade versus stimulation, respectively. Each of the two tasks provides some information not available in the other. The forced choice task demonstrates differential learning from positive and negative feedback that is unconfounded by simple motor effects, as a single motor command is required on each choice trial. In contrast, the Go/No-Go task allowed us to measure an overall Go response bias, which was present for the low-span group receiving cabergoline as predicted by the postsynaptic $\mathrm{D}_{2}$ stimulation hypothesized to occur in this group. Overall, the converging evidence from both tasks supports the BG/DA modeling framework.

\section{Cognitive Task III: Working Memory and Executive Function}

\section{Procedure}

In the third task, we test the implications of the model in higher level executive function and working memory. To do so, we use a common 
a)

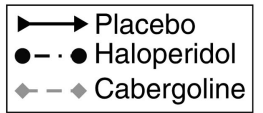

Probabilistic Go/NoGo Test Performance

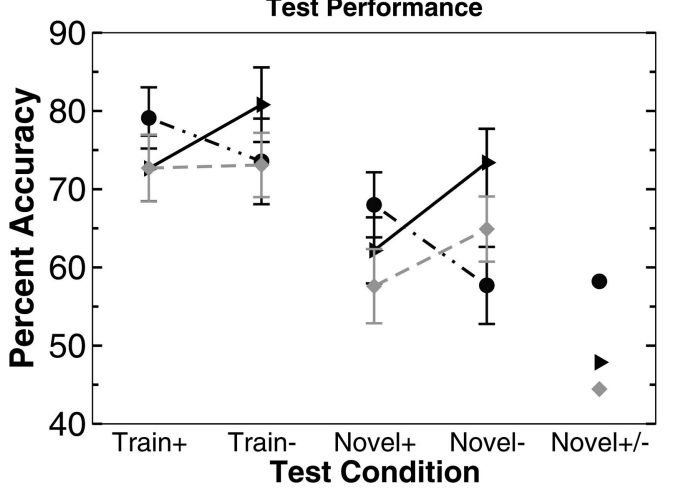

b)

Figure 6. (a) Probabilistic Go/No-Go accuracy in a test phase, in which single patterns from the training phase and all possible two-way combinations of these patterns are presented without feedback. Overall, the results show the same crossover interaction as in the probabilistic selection task, for the same hypothesized reason: Haloperidol exhibits greater Go versus No-Go learning due to enhanced dopamine (DA) bursting, whereas cabergoline impairs Go learning due to decreased DA bursting. Train $+=$ single training stimuli associated with positive reinforcement (pooled $80 \%, 70 \%$, and $60 \%$ correct feedback); Train $-=$ training stimuli associated with negative reinforcement (pooled $80 \%, 70 \%$, and $60 \%$ incorrect feedback). Because training stimuli can be memorized, a better test of relative Go/No-Go learning comes from the novel test pairs. Novel $+=$ novel combinations of training patterns that together have a more positive than negative association (e.g., the left half of the composite pattern was an $80 \%$ Go stimulus, whereas the right half was a $60 \%$ No-Go stimulus); Novel$=$ novel combinations of training stimuli that have an overall negative association; Novel $+/-=$ combined test pairs that have equal positive and negative associations (in this case there is no correct response, so plotted values represent simply percentage of Go responding). (b) Cabergoline (Cab) modulation of Go responding (resp) interacted with working memory span, such that low-span cabergoline participants responded Go to positive stimuli (pos stims) numerically more often than participants administered placebo (Plac), whereas high-span cabergoline participants responded significantly less often than those administered placebo. These results are consistent with counteracting pre- and postsynaptic performance and learning effects in low-span cabergoline participants, whereas high-span cabergoline participants might have been more sensitive to presynaptic-mediated reduced DA bursts leading to impaired Go learning.

working memory paradigm called the AX-CPT (continuous performance task; Barch et al., 1997, 2001; Servan-Schreiber et al., 1997). We also modified the task to include distractors (Braver et al., 2001) and added reversal and attentional-shifting conditions. We used both short (1-s) and long (3-s) delay conditions and variable numbers of distractors (0-3) in the long delay. We also included a learning version, where participants had to learn the target sequence through trial and error. In the basic task, the participant is presented with sequential letter stimuli (A, X, B, Y; printed in red) and is asked to detect the specific sequence of an " $\mathrm{A}$ " (cue) followed by an " $X$ " (probe) by pushing the right button (see Figure 7). The participant is instructed to respond to all other cue-probe combinations (A,Y; B,X; B,Y) with a left-button push. In the short-delay case, the delay between cue and probe is $1 \mathrm{~s}$. The target A,X sequence occurs on $70 \%$ of trials, and the other sequences are divided equally by the remaining $30 \%$ of trials. This task requires a relatively simple form of working memory, where the prior stimulus must be maintained over a delay until the next stimulus appears, so that one can discriminate the target from nontarget sequences.

This task also allows analysis of the type of errors made (Barch et al., 1997; Braver et al., 2001). If participants successfully maintain contextual information (e.g., A) in working memory, then they will perform well at detecting the $\mathrm{A}, \mathrm{X}$ target sequence but will likely make more false positive errors on the A,Y sequence (as a result of anticipation of an X). Context maintenance also should improve performance on the $\mathrm{B}, \mathrm{X}$ case, because one can use the $\mathrm{B}$ to know not to respond to the $\mathrm{X}$ as a target. The $\mathrm{B}, \mathrm{Y}$ sequence serves as a control, because neither the $\mathrm{B}$ nor the $\mathrm{Y}$ are associated with the target. Furthermore, because the A,X sequence occurs with high (70\%) probability, it is not as reliable an indicator of working memory performance because participants can simply learn a prepotent response to stimulus X. Thus, we focused instead on the B,X and A,Y cases (where increased maintenance produces worse performance). Specifically, we computed a working memory context index by subtracting percentage of $\mathrm{A}, \mathrm{Y}$ accuracy from that of $\mathrm{B}, \mathrm{X}$. A positive working memory context index indicates greater influence of working memory on choice behavior, whereas a negative context index indicates that choices are being dictated by incoming stimuli and are not influenced by working memory (Braver et al., 2001).

In the learning version, participants must figure out the target sequence by trial and error. As in the standard $\mathrm{AX}$ task, letters $(\mathrm{H}, \mathrm{K}, \mathrm{Z}, \mathrm{P})$ are presented sequentially one at a time. No distractors are present, because this segment is already fairly difficult. Participants are instructed to press the left button for each cue and the right button when they think they have seen the target sequence (initially by guessing). After each probe stimulus, feedback informs the participant whether they were correct or incorrect. This task may depend more on phasic DA signals modified by the drugs than the standard working memory tasks. Further, this version may corre- 


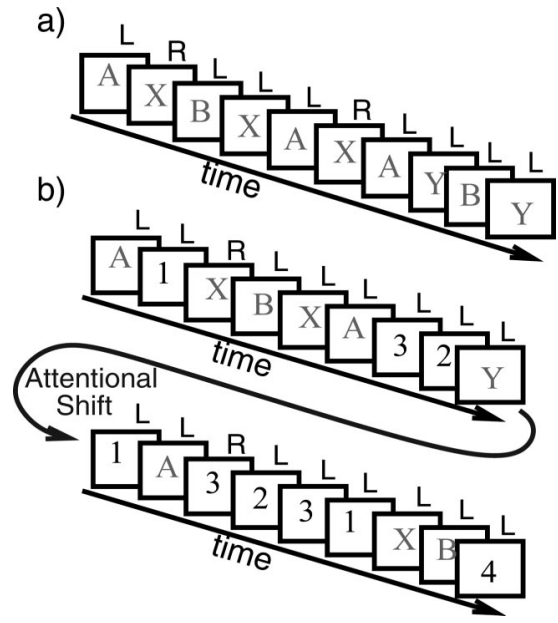

Figure 7. The AX continuous performance task (AX-CPT). (a) Standard version. Stimuli are presented one at a time in a sequence. The participant responds by pressing the right key (R) to the target sequence; otherwise, a left key (L) is pressed. Delay between each stimulus is $1 \mathrm{~s}$. The A,X target sequence occurs on $70 \%$ of trials, building up a prepotent expectation for target responses. (b) Variable distractors. The task is the same as in the standard version, but anywhere from zero to three distractors are presented sequentially during a 3-s delay period. Participants are instructed to respond to distractors with a left button push but are told to ignore these for the purpose of target detection. In a subsequent attentional shift, the target sequence consists of previously distracting number stimuli $(1,3)$, and the letter stimuli are now distractors.

spond better to working memory tasks used in nonhuman primate experiments, in which animals must learn which working memory representations to reinforce via reward or lack thereof.

In our BG/PFC framework, we argue that BG Go signals lead to the updating of PFC working memory representations, ${ }^{5}$ and that DA enhances Go signals, leading to a lowered updating threshold (Frank et al., 2001; Frank, 2005; see also Redgrave, Prescott, \& Gurney, 1999a; Weiner \& Joel, 2002). Further, DA bursts may occur for task-relevant (i.e., positive) information, making this information more likely to become updated and subsequently maintained (Hazy, Frank, \& O'Reilly, in press; O'Reilly \& Frank, 2006). Therefore, we hypothesized that low-span participants receiving haloperidol, who have enhanced DA bursts, should be more likely to update and maintain task-relevant information in working memory. This should be particularly true for the learning version, which most clearly depends on DA bursts during positive feedback. The converse should also be the case for the high-span group receiving cabergoline, where decreased DA bursting should lead to less working memory updating for task-relevant information. These effects should be particularly apparent in the attentional-shifting condition, in which previously task-relevant information becomes distracting and previously distracting information becomes relevant, requiring Go learning to update new information.

The predictions for low-span participants receiving cabergoline are perhaps the most interesting in this task. Here, we expect that the overall Go bias (via postsynaptic $\mathrm{D}_{2}$ receptor stimulation) should lead to both enhanced working memory updating but also increased distractibility because of inappropriate updating of the distractor stimuli (for similar ideas regarding BG DA, see Bilder et al., 2004; Cools, 2005). This illustrates a key difference between these postsynaptic effects and DA bursts controlled by presynaptic receptors. The increased DA bursts for low-span haloperidol should not increase distractor updating, because these distractors are not task relevant, and should not trigger a DA burst (O'Reilly \& Frank, 2006). In contrast, a Go bias induced by postsynaptic $\mathrm{D}_{2}$ receptor stimulation should produce an overall greater propensity for BG Go signals for all stimuli, whether task relevant or not. This is similar to the tonic Go bias observed in low-span participants receiving cabergoline across both cognitive procedural learning tasks, described above. Note that similar predictions can be made from a purely prefrontal hypothesis of DA function (Durstewitz \& Seamans, 2002; Seamans \& Yang, 2004) but that this would require the drug effects on DA bursting and release to extend to PFC, which we argue is unlikely (see Figure 2b); we return to this issue in the General Discussion.

\section{Results and Discussion}

Figure 8 shows the results for the standard AX task, the distractor condition, and the learning version. As predicted, haloperidol resulted in enhanced working memory updating, particularly significantly in the learning task, standard $F(1$, $26)=3.8, p=.06$; learning $F(1,26)=6.7, p=.016$ (both relative to placebo). This is consistent with enhanced DA bursts supporting BG Go signals and thus working memory updating. Further, the working memory enhancement in the learning version was significant in the low-span participants, $F(1,26)=$ $9.98, p=.004$, but not in the high-span participants, $F(1,26)=$ 0.15 . Cabergoline significantly enhanced working memory in the standard version, $F(1,26)=12.3, p=.0016$, consistent with the postsynaptic Go bias effect leading to more overall working memory updating. This same Go bias effect may have counteracted any Go learning deficits in the learning version, consistent with a null behavioral effect of cabergoline on working memory context in this version, $F(1,26)=0.2$.

Our inclusion of distractors during the delay was meant to test the role of BG gating of PFC working memory representations. Specifically, if participants inadvertently update these distractors into PFC, they could interfere with existing working memory representations. Indeed, there was a large main effect of distractors on working memory context index, $F(1,26)=$ $10.4, p=.003$, such that it was significantly decreased when distractors were present compared with no-distractor trials. Notably, this distractibility effect was even worse under cabergoline, $F(1,26)=4.5, p=.04$ (Figure 8), despite the fact that the same drug enhanced working memory in the standard (short-delay) version. Moreover, in the long-delay condition, a crossover interaction was observed in the low-span participants such that working memory context was enhanced relative to placebo in no-distractor trials but was impaired when distractors were present, $F(1,26)=9.4, p=.005$. This interaction was not observed in high-span participants, $F(1,26)=0.5, n s$. This crossover interaction, which is not consistent with overall performance improvements or decrements, provides a nice confirmation of how the BG/DA system can influence working memory updating (Frank, 2005; Frank et al., 2001; O'Reilly \& Frank, 2006) and suggests that lowering the overall threshold for updating is not always adaptive.

We also validated our working memory context index measure (\% correct of $\mathrm{B}, \mathrm{X}$ minus $\%$ correct of $\mathrm{A}, \mathrm{Y}$ ) by showing that it has a significant negative correlation with number of errors in the working memory span test $(r=-.48, p=.01$; as based on

\footnotetext{
${ }^{5}$ By "updating" we mean replacing the contents of previously maintained PFC representations to store new information.
} 


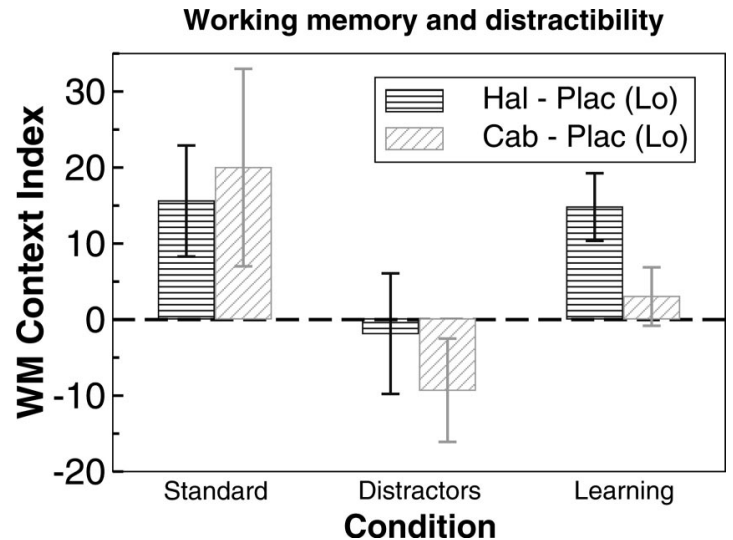

Figure 8. Within-subject (relative to placebo) AX continuous performance task working memory results for the standard version, the distractors condition, and the learning version (where the target sequence must be learned through trial and error) of the task. Working memory context index $=\%$ correct of $\mathrm{B}, \mathrm{X}$ minus $\%$ correct of $\mathrm{A}, \mathrm{Y}$, measuring maintenance of context information $(\mathrm{A}, \mathrm{B})$ in working memory. Haloperidol enhanced working memory in low-span participants, which was especially significant in the learning version of the task. This is consistent with increased dopamine bursting for task-relevant stimuli, reinforcing basal ganglia Go signals to update prefrontal cortex working memory representations. Cabergoline ( $\mathrm{Cab}$ ) also enhanced working memory in low-span participants in the standard condition, but unlike haloperidol (Hal), this drug actually impaired working memory when distractors were presented during the delay. Thus these results are consistent with a tonic postsynaptic Go bias in low-span cabergoline participants, causing an overall lowered threshold for updating working memory and increased distractibility. In contrast, haloperidol was not associated with impaired working memory when distractors were present, consistent with predictions, as these should not elicit a DA burst. Counteracting pre- and postsynaptic effects may have led to a null behavioral effect for cabergoline in the learning condition. Plac $=$ placebo.

placebo data, because the working memory span test was only performed in prescreening sessions without drugs). Furthermore, to ensure that drug effects were genuinely related to working memory, we analyzed performance in the B-Y control trials, in which performance does not depend on working memory. There was no main effect of drug on performance in these trials, $F(2,26)=0.94, n s$, and no effect of either cabergoline, $F(1,26)=0.23$, or haloperidol, $F(1,26)=1.86, n s$, relative to placebo. There was also no main effect of drug on $\mathrm{A}, \mathrm{X}$ target responding, $F(2,26)=1.3, n s$, and no effect of either cabergoline, $F(1,26)=0.65$, or haloperidol, $F(1,26)=2.6, n s$, relative to placebo.

\section{Reversal and Attentional Shifting}

\section{Procedure}

As in the Go/No-Go procedural learning task, we were also interested in the effects of the drugs on reversal and attentional shifting. These processes are typically associated with prefrontal function, but they also require updating task-relevant versus irrelevant stimulus information. For the reversal case, we reversed the target sequence from $\mathrm{A}, \mathrm{X}$ to $\mathrm{B}, \mathrm{Y}$. We predicted that the overall Go bias effect for the low-span group receiving cabergoline would make it particularly difficult to stop responding to the $\mathrm{A}, \mathrm{X}$ trials. Further, this perseverative responding should only occur in zero-distractor A,X trials: When distractors are present, cabergoline should continue to increase working memory updating and should therefore lead to less anticipation of $\mathrm{A}, \mathrm{X}$ sequences and less perseveration. No effect of DA bursting (e.g., low-span participants receiving haloperidol) was expected in reversal, because the hypothesized effect on DA bursting to task-relevant information does not change in this case (i.e., the $[\mathrm{A}, \mathrm{X}, \mathrm{B}, \mathrm{Y}]$ letters that were task-relevant in the $\mathrm{A}, \mathrm{X}$ segment continue to be taskrelevant in the B,Y segment).

For the attentional-shifting case, we swapped the targets and distractors, making the target sequence 1,3 (vs. 2,$3 ; 1,4 ; 2,4$ ) while the letters $\mathrm{A}, \mathrm{X}, \mathrm{B}$ and $\mathrm{Y}$ became distractors. A final reversal switched the target to 2,4. Our computational model predicts that it is precisely this kind of situation for which DA bursts in the BG are critical for the updating of new taskrelevant information into PFC working memory representations (Frank, 2005; O'Reilly \& Frank, 2006; see also Redgrave et al., 1999a; Weiner \& Joel, 2002). As in the probabilistic learning task, these DA bursts also reinforce this updating so that task-relevant stimuli will be more easily updated in the future. In this context, there are at least two possible sources of DA-related attentional-shifting deficits. For the high-span group receiving cabergoline, diminished DA bursts should result in impaired Go signals to update the new task-relevant set, which should now be more evident given the prior learning to ignore these stimuli. In contrast, for low-span participants receiving haloperidol, enhanced DA bursting to task-relevant stimuli in the initial segment should have built up Go learning, leading to difficulty ignoring these stimuli when they subsequently become distracting.

\section{Results and Discussion}

Reversal results. As predicted, low-span participants receiving cabergoline perseverated on the old target sequence $(\mathrm{A}, \mathrm{X})$ in the reversal segment significantly more than placebo. Notably, this deficit interacted with distractors, $F(1,26)=6.8, p=$ .01 . Specifically, increased perseveration was observed in nodistractor trials, $F(1,26)=4.7, p=.039$, consistent with a Go bias leading to more prepotent responding to old targets. However, low-span participants receiving cabergoline also showed a trend for better performance than placebo in distractor trials, $F(1,26)=3.0, p=.095$, consistent with the idea that the same Go bias effect caused updating of these distractors and therefore less target anticipation. There was no such interaction between perseveration and distractors for high-span participants receiving cabergoline, $F(1,26)=0.39, n$ s, who did not differ from placebo either in the zero-distractor condition, $F(1,26)=0.0$, or in the presence of distractors, $F(1,26)=1.05, n s$. Further, there were no effects of haloperidol on perseveration to old target sequences, $F(1,26)=0.02$. Overall, there was no main effect of drug on the ability to respond to new target sequences, $F(2,26)=0.7$, and no drug interaction with distractors, $F(2$, 26) $=0.35$.

Attentional-shifting results. Overall performance decrements in the attentional-shifting segment were observed for both cabergoline, $F(1,26)=5.25, p=.03$, and haloperidol, $F(1,26)=4.7$, $p=.039$, relative to placebo. Nevertheless, the drugs had opposite effects on two distinct aspects of attentional shifting in the two different span groups (see Figure 9). High-span participants receiving haloperidol were specifically impaired at attending to the newly task-relevant stimuli, whereas low-span participants receiving haloperidol were impaired at ignoring the previously relevant stimuli. To measure the ability to attend to the newly task-relevant stimuli (numbers), we used performance on no-distractor trials, which only contained these number stimuli. To measure difficulty in ignoring previously task-relevant stimuli (letters), we used per- 
a)

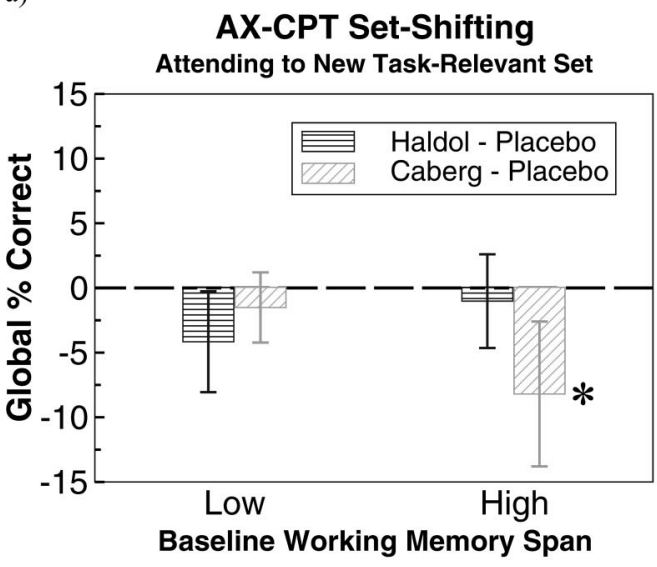

c)

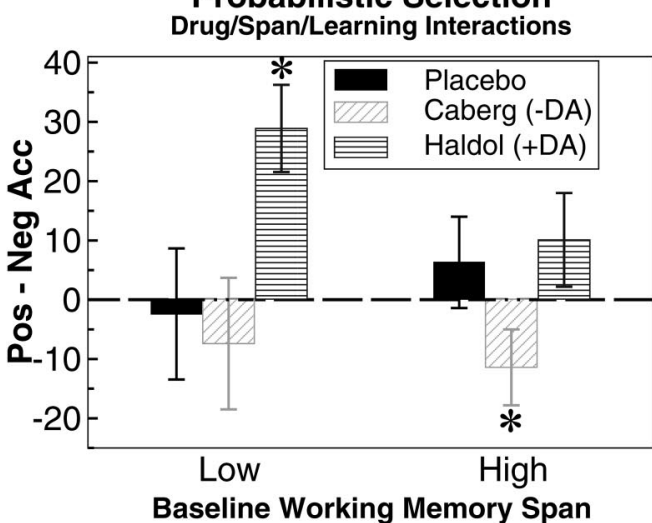

b)

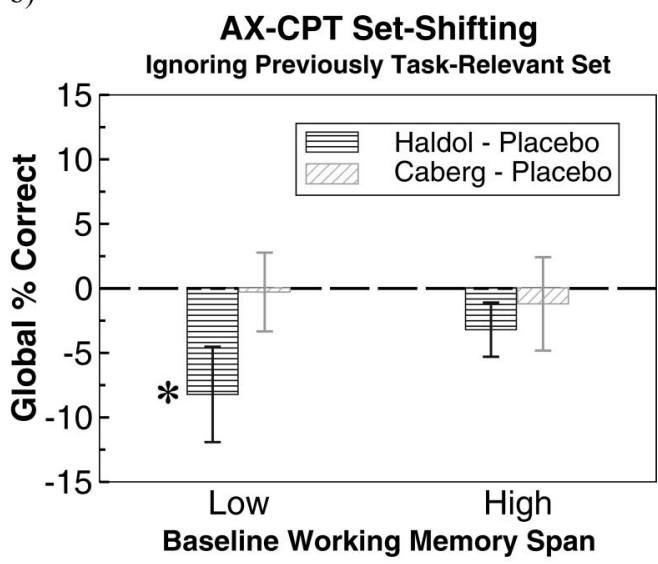

d)

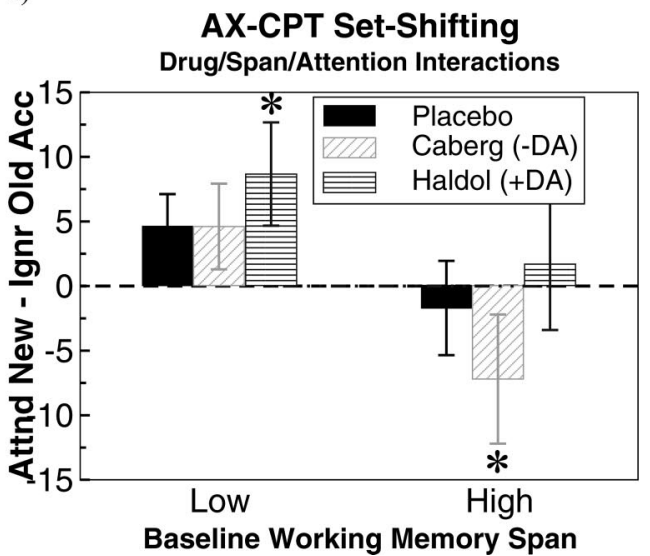

Figure 9. Attentional-shifting results, broken down into low- and high-span participants and drug effects relative to placebo. (a) Shifting deficits in the AX continuous performance task (AX-CPT) under cabergoline (Caberg), in terms of difficulty attending to a previously distracting set, were observed in high-span participants. These deficits were evident by global performance decrements in the zero-distractor condition during the initial $(1,3)$ attentional-shifting segment. That the deficits were observed only in high-span participants is consistent with the Go learning deficit induced by cabergoline in these participants in both procedural learning tasks. In low-span participants, the Go bias effect to update all stimuli may have masked an otherwise Go learning deficit. Haloperidol (Haldol) was not associated with attentional-shifting deficits in the zero distractor condition. (b) Attentional-shifting deficits under haloperidol, in terms of difficulty ignoring previously task-relevant letters when these letters subsequently became distractors. This is consistent with the hypothesis that the drug enhanced dopamine (DA) bursts for the letter stimuli during the initial $\mathrm{A}, \mathrm{X}$ and $\mathrm{B}, \mathrm{Y}$ segments, making them difficult to subsequently ignore. As in procedural learning tasks, haloperidol effects were only observed in low-span participants. (c) Working memory span results for the probabilistic selection task, showing increased Go relative to No-Go learning in low-span haloperidol participants, with the opposite effects in high-span cabergoline participants. (d) Analogous effects for attentional shifting, showing relatively better attend-new than ignore-old performance in low-span haloperidol participants (as predicted by enhanced DA bursts), with the opposite effects in high-span cabergoline participants (reduced DA bursts). Acc = accuracy.

formance when these letters were included as distractors during the delay. High-span participants receiving cabergoline were impaired relative to placebo for the no-distractor case, $F(1,26)=9.9, p=$ .004 , with no significant impairments for distractors, $F(1,26)=$ 0.78. The opposite pattern was observed for low-span participants receiving haloperidol, for whom performance was significantly worse than placebo on distractor trials, $F(1,26)=12.15, p=$ .0018 , but not in no-distractor trials, $F(1,26)=0.23$.
Overall, the results for the low-span participants receiving haloperidol are consistent with our hypothesis that enhanced DA bursts supported and reinforced selective working memory updating of the task-relevant letters in the initial stages, which then made it more difficult to ignore these stimuli when they subsequently became distractors. In contrast, the results for high-span participants receiving cabergoline are consistent with diminished DA bursts to support Go signals to update newly task relevant 
Table 2

Summary of Behavioral Results in Procedural Learning and Working Memory as a Function of Drug and Working Memory Span Groups, and Associated Biological Effects

\begin{tabular}{|c|c|c|c|}
\hline \multirow{2}{*}{$\begin{array}{l}\text { Effects (relative } \\
\text { to placebo) }\end{array}$} & \multicolumn{3}{|c|}{ Drug/working memory span group } \\
\hline & Low-span haloperidol & High-span cabergoline & Low-span cabergoline \\
\hline \multicolumn{4}{|l|}{ Biological } \\
\hline Prolactin & $\uparrow$ & $\downarrow$ & $\downarrow \downarrow$ \\
\hline Relative drug efficacy & Medium & Medium & Highest \\
\hline$D_{2}$ receptors & Pre block & Pre stimulate & Pre and post stimulate \\
\hline DA bursts, Go/No-Go & $\uparrow$ DA bursts & $\downarrow$ DA bursts & $\downarrow$ DA bursts, $\uparrow$ Go \\
\hline \multicolumn{4}{|l|}{ Procedural learning } \\
\hline Performance & - & - & Faster RT \\
\hline Learning & $\uparrow$ Go & $\downarrow$ Go & $\uparrow \downarrow$ Go \\
\hline Reversal & $\uparrow$ Go (old) & $\downarrow$ Go (new) & $\uparrow \downarrow$ Go \\
\hline \multicolumn{4}{|l|}{ Working memory } \\
\hline Working memory updating & $\uparrow$ Go (task-relevant) & $\downarrow$ Go & $\uparrow$ Go (all stimulus) \\
\hline Learning & $\uparrow$ Go (task-relevant) & $\downarrow$ Go & $\uparrow \downarrow$ Go \\
\hline Distractibility & - & - & Go \\
\hline Reversal & - & - & $\uparrow$ Go (previous target) \\
\hline Attentional-shifting & $\uparrow$ Go (previous target) & $\downarrow$ Go (previous distractor) & $\uparrow \downarrow$ Go \\
\hline
\end{tabular}

Note. No biological or behavioral effects were observed among high-span haloperidol participants. Hypothesized biological drug effects on $\mathrm{D}_{2}$ presynaptic (pre) and postsynaptic (post) receptors are constrained by their observed effects on prolactin and by existing knowledge on the greater presynaptic sensitivity. Behavioral results for low-span haloperidol and high-span cabergoline participants were consistent with enhanced and reduced dopamine (DA) bursts, respectively. For low-span cabergoline participants, postsynaptic $\mathrm{D}_{2}$ stimulation may have led to an overall Go bias, which counteracts the presynaptic reduction of DA bursts. When DA bursts are not expected, the Go bias effect dominates. $\mathrm{RT}=$ reaction time .

stimuli. Notably, these Go deficits were only evident for previously ignored stimuli, for which they would likely need to overcome prior BG No-Go signals. ${ }^{6}$

\section{General Discussion}

Taken together, the results of our studies support an emergent, unified framework for BG DA function that cuts across a range of cognitive domains. This framework goes beyond descriptive theories emphasizing that the BG system is involved in a particular cognitive task to attempt to explicitly address how DA modulation within the BG affects cognition. By adopting this mechanistic approach, motivated through explicit computational simulations, our framework reconciles findings of cognitive enhancements and impairments that interact with drug, dose, working memory span, and task conditions.

In brief, our framework suggests that DA dynamically modulates BG Go and No-Go signals that facilitate and suppress the execution of cortical actions, respectively. Furthermore, Go signals can trigger the updating of working memory representations in prefrontal cortex. Positive reinforcement drives DA bursting that enhances Go firing and learning, whereas negative feedback has the opposite effects. These DA effects are modulated in two opposing ways by pre- and postsynaptic $\mathrm{D}_{2}$ receptors. Presynaptic autoreceptors control the level of DA release in phasic bursts via inhibitory feedback (Schoemaker et al., 1997), whereas postsynaptic receptors are predominantly localized in the No-Go pathway and have inhibitory effects when stimulated by DA or agonists. The presynaptic autoreceptors are more sensitive than the postsynaptic ones, which enabled us to dissociate their effects as a function of the overall efficacy of two $\mathrm{D}_{2}$ receptor drugs: cabergoline (agonist) and haloperidol (antagonist).

Consistent converging evidence suggests that overall drug effi- cacy interacted with individual differences in working memory span such that low-span participants exhibited stronger drug effects than those with high-span working memory. Furthermore, cabergoline had stronger overall effects than haloperidol. These effects were observed both biologically, in terms of drug effects on serum prolactin levels, and behaviorally. Thus, the low-span cabergoline group had the highest overall drug efficacy, and the behavioral results were consistent with both pre- and postsynaptic effects (reduced DA bursts from presynaptic stimulation, overall Go bias due to postsynaptic No-Go inhibition). The high-span cabergoline group had lower drug efficacy, with putatively selective presynaptic effects (reduced DA bursts). The low-span haloperidol group had similar efficacy to the high-span cabergoline group and also exhibited predominantly presynaptic effects (increased DA bursts from autoreceptor antagonism). Finally, the high-span haloperidol group had the least drug efficacy and exhibited no drug effects at all (see Figure 3 for a summary).

A summary of the primary results found in this study provides overwhelming support for the general predictions of these models (see Table 2). Participants in the low-span haloperidol group showed increased Go learning across all tasks and increased updating (i.e., Go signals) for task-relevant stimuli in the working

\footnotetext{
${ }^{6}$ One might expect that an updating deficit under cabergoline would be seen regardless of whether distractors were present. However, the lack of impairment under the distractor condition is actually consistent with the hypothesis that the drug reduced DA bursts to the task-relevant information in the initial set, making them easier to subsequently ignore; this may have partially counteracted the deficit in updating the new set, leading to nonsignificant impairments when distractors were present (for data see Table 4 in supplementary information on the Web at http://dx.doi.org/ 10.1037/0735-7044.120.3.497.supp).
} 
memory task, consistent with increased DA bursting due to blockade of presynaptic DA receptors. The high-span cabergoline group showed the opposite pattern across all tasks, consistent with decreased DA bursting due to stimulation of presynaptic DA receptors. The low-span cabergoline group had different effects, consistent with conflicting pre- and postsynaptic mechanisms. First, this group had faster RTs in the probabilistic selection task, which is a clear indication of postsynaptic No-Go inhibition effects. In addition, this group exhibited the signature effect of enhanced Go signals across the board in the working memory task, namely, increased working memory performance without distractors, but significant impairments with distractors.

\section{Relationship to Other Studies}

Our findings are consistent with those of several other studies in which dopaminergic agents were administered. First, the opposite effects of cabergoline and haloperidol on $\mathrm{Go} / \mathrm{No}-\mathrm{Go}$ learning directly replicate our prior results in Parkinson's patients, which were reversed by DA medication (Frank et al., 2004; Figure 4c). Diminished DA bursts in the BG during positive feedback, caused by either Parkinson's disease or by cabergoline administration, resulted in better learning from negative than from positive feedback. Increased release of BG DA, caused either by L-dopa medication in Parkinson's disease or by haloperidol administration, resulted in better learning from positive feedback. Second, our cabergoline results showing reversal learning impairments are consistent with similar impairments in participants taking bromocriptine (also a $\mathrm{D}_{2}$ agonist; Mehta et al., 2001). Notably, in that study, bromocriptine also improved performance in a spatial working memory task. Because that task only involved task-relevant stimuli (no distractors), this improvement is also consistent with cabergoline effects in our study. Finally, cabergoline deficits in attending to a previously irrelevant stimulus category are consistent with similar attentional-shifting deficits in patients with Parkinson's disease (Owen et al., 1993). According to our and others' theoretical and modeling frameworks (Redgrave et al., 1999a; Weiner \& Joel, 2002), DA bursts are required to shift attention to new information, and both cabergoline and Parkinson's disease would diminish these bursts.

Overall, our results raise the question as to why $\mathrm{D}_{2}$ drugs should have larger effects in low-span participants. Most accounts of span-dependent drug effects rely on observations that proficient working memory is associated with an optimal level of DA or $\mathrm{D}_{1}$ receptor stimulation in PFC (Arnsten, 1997; Phillips, Ahn, \& Floresco, 2004; Williams \& Goldman-Rakic, 1995). Such an account suggests that DA agonists enhance performance in low-span participants by increasing their low-DA levels but may cause excessive DA stimulation in those with high span who already have an optimal DA level (Kimberg et al., 1997; Mattay et al., 2000). The present results point to a somewhat different account. First, we suggest that the BG is a more relevant locus of $D_{2}$ drug effects rather than PFC (see below for further discussion). Second, we suggest that biological differences between low- and high-span participants may include differential sensitivity to $D_{2}$ receptor stimulation rather than overall differences in DA levels. However, it may be possible to reconcile these two accounts, by suggesting that low tonic levels of DA in low-span participants leave the $\mathrm{D}_{2}$ receptor more susceptible to influence from the $\mathrm{D}_{2}$ drugs, whereas the higher levels of DA in high-span participants cause the drug effects to be relatively diluted through receptor binding competition.

As noted earlier, span-dependent bromocriptine effects on working memory have also been reported (Kimberg et al., 1997). In that study, low-span participants improved in attentional shifting, whereas high-span participants were impaired. Our findings suggest that these results may have stemmed from differential receptor effects of the agonist across span groups. Specifically, the overall Go bias effect in low-span participants may have resulted in enhanced working memory updating overall. In contrast, selective reduction of DA bursts in high-span participants may have caused deficits in updating new task-relevant information in attentionalshifting conditions. Consistent with this account, in the present study, we observed Go learning impairments in reversal and attentional-shifting conditions only in the high working memory span participants on cabergoline. This account is also consistent with more recent observations that bromocriptine led to speeded reaction times only in low-span participants (Gibbs \& D'Esposito, 2005). More generally, our findings that dopaminergic agents have span-dependent effects even on lower level cognitive tasks is consistent with a recent animal study showing that low working memory performance was predictive of greater locomotor response to amphetamine (Dellu-Hagedorn, 2005) and with baseline performance-dependent effects of a $\mathrm{D}_{4}$ antagonist on working memory (Zhang et al., 2004). Future neuroimaging studies should investigate potential span-dependent differences in human brain activity in response to $\mathrm{D}_{2}$ agents.

Although haloperidol typically has sedative effects when used clinically, we argue that these effects are due to postsynaptic blockade associated with higher doses and/or chronic administration. Indeed, in our study there was no effect of haloperidol on alertness, drowsiness, or other measures (see supplementary materials on the Web at http://dx.doi.org/10.1037/07357044.120.3.497.supp). Instead, our results are consistent with animal studies showing that at single low doses, $\mathrm{D}_{2}$ antagonists enhance DA release (Garris et al., 2003; Moghaddam \& Bunney, 1990; Wu et al., 2002) and enhance incentive (Go) learning (Eyny \& Horvitz, 2003; J. K. Smith, Neill, \& Costall, 1997). In both animals and humans, the phenomenon of latent inhibition is disrupted with enhanced DA release (e.g., Gray, Pickering, Hemsley, Dawling, \& Gray, 1992). This effect was also recently observed with low-dose $\mathrm{D}_{2}$ antagonists (Barrett, Bell, Watson, \& King, 2004) and is consistent with enhanced Go learning observed in the present study, which would disrupt latent inhibition. Further, the attentional-shifting deficits under haloperidol in our study are consistent with similar attentional-shifting impairments under sulpiride, another $\mathrm{D}_{2}$ antagonist (Mehta et al., 1999, 2004). Whereas Mehta et al. (1999) interpreted their results as evidence for sulpiride simulating the cognitive profile of Parkinson's disease patients, we emphasize that blocking $\mathrm{D}_{2}$ receptors in healthy participants may actually increase DA release during bursts. This contrasts with the lack of available DA associated with Parkinson's disease. Therefore, we suggest that the observed attentionalshifting impairments under sulpiride may have arisen instead as a result of presynaptic enhancement of DA bursts before the shift, causing excessive attention to the previously relevant dimension. This is consistent with the fact that basic RTs were not slowed in those studies, as would be expected from a postsynaptic effect. Moreover, a presynaptic increase in DA bursting by sulpiride could explain recent observations from the same group that the 
drug increased distractibility in a working memory task when distractors were task relevant (and could therefore elicit DA bursts and cause working memory updating) but not when distractors were irrelevant (Mehta et al., 2004). Furthermore, they also showed that sulpiride can enhance trial and error learning (Mehta, Hinton, Montgomery, Bantick, \& Grasby, 2005), presumably via enhanced DA bursts during positive reinforcement. Nevertheless, higher dose antagonists should have significant postsynaptic effects, resulting in an overly active No-Go pathway and may come closer to simulating Parkinson's disease.

\section{Are $D_{2}$ Agents Selective for the Basal Ganglia?}

We have argued that the behavioral effects of the $\mathrm{D}_{2}$ drugs are primarily a result of their action in the $\mathrm{BG}$, as compared with the PFC or other areas, based on a number of converging sources of evidence. Anatomically, $\mathrm{D}_{2}$ receptors are 11 times more prevalent in striatum than in frontal cortex (Camps et al., 1989). Higher levels of $\mathrm{D}_{2}$ stimulation than are likely produced by the low medication doses are required to functionally affect prefrontal activity states (Seamans \& Yang, 2004). Trantham-Davidson, Neely, Lavin, and Seamans (2004) found that at least twice the level of DA is required to functionally affect PFC $D_{2}$ receptors compared with $\mathrm{D}_{1}$ receptors. Notably, enhanced DA release by single doses of haloperidol are selective to the BG, with DA levels in frontal cortex relatively unaffected (Chen et al., 2005; Kuroki et al., 1999; Moghaddam \& Bunney, 1990; Pehek, 1999; Westerink, 2002). In humans, $D_{2}$ agents have been shown to modulate striatal, but not prefrontal, blood flow (Honey et al., 2003; Mehta et al., 2003). Behaviorally, $D_{2}$ agents affect working memory processes when applied systemically but not when directly infused into PFC (Arnsten, Cai, Murphy, \& Goldman-Rakic, 1994; Arnsten, Cai, Steere, \& Goldman-Rakic, 1995; Sawaguchi, 2001; Yang \& Seamans, 1996), suggesting that they exert their effects elsewhere. In contrast, $\mathrm{D}_{1}$ receptor stimulation/blockade directly in PFC have profound effects on working memory processes (Durstewitz \& Seamans, 2002; Sawaguchi, 2001; Sawaguchi \& Goldman-Rakic, 1991; Williams \& Goldman-Rakic, 1995). In a recent study, Wang, Vijayraghavan, and Goldman-Rakic (2004) showed that blocking $\mathrm{PFC}_{1}$ receptors reduced working memory-related neural activity, whereas blocking $P F C \mathrm{D}_{2}$ receptors only reduced movement-related activity occurring at the end of a delay period, with no reported effect on behavioral performance. ${ }^{7}$

\section{Dopamine Effects in Prefrontal Cortex: $D_{1}$ and $D_{2}$ Receptors}

Although the above data support our focus on the BG in this study, there are clearly important effects of DA modulation within the PFC. For example, biophysical computational models have clarified the precise mechanisms by which $\mathrm{D}_{1}$ stimulation enhances persistent PFC neural activity while making this activity less susceptible to interference (Durstewitz \& Seamans, 2002; Durstewitz, Seamans, \& Sejnowski, 2000). These models provide important theoretical contributions for understanding PFC DA function in working memory and executive function and support the general notion that DA increases the signal-to-noise ratio of activity within PFC (Cohen, Braver, \& Brown, 2002; Durstewitz \& Seamans, 2002; Servan-Schreiber, Printz, \& Cohen, 1990). Without sufficient DA in the PFC, task-related activity is more susceptible to interference and is therefore less stable (Durstewitz et al., 2000).
An outstanding question is to what degree DA within the PFC can support rapid updating of information, as has been hypothesized by several authors (Braver \& Cohen, 2000; Cohen et al., 2002; Rougier \& O'Reilly, 2002; Seamans \& Yang, 2004; Tanaka, 2002). Because DA signals onto $P F C D_{1}$ receptors are delayed and temporally extended (Seamans, Gorelova, Durstewitz, \& Yang, 2001), they may be suitable for enhancing maintenance capabilities over many seconds but may be less likely to support rapid updating in a very short time window (Dreher \& Burnod, 2002; Lavin et al., 2005; Seamans \& Yang, 2004). In contrast, we argue that phasic DA effects are critical for learning and updating in the $\mathrm{BG}$, where DA uptake speed is much faster owing to a far greater concentration of DA transporters (Cragg, Hille, \& Greenfield, 2002; Sesack, Hawrylak, Matus, Guido, \& Levey, 1998). Further, if phasic DA bursts within PFC supported updating, the diffuseness of DA release would result in all PFC representations getting updated with each DA burst. This would not allow for selective updating of some information while maintaining existing information already stored in PFC. Selective updating is necessary in many aspects of executive function, in which higher level goals should be maintained while lower level subgoals can be continuously updated. This problem is avoided if the gating function occurs via the $\mathrm{BG}$, because a Go signal in one part of the BG can update only a corresponding subregion of frontal cortex via parallel-loop connectivity (Frank, 2005; Frank et al., 2001; Hazy et al., in press; O'Reilly \& Frank, 2006).

Nevertheless, it is plausible that whereas BG Go/No-Go signals modulate what regions of PFC to update, global ventral tegmental area (VTA) bursts can additionally modulate when to update. For example, phasic VTA stimulation has been shown to drive fast membrane potential transitions in PFC that could support rapid updating, via non-DA mechanisms (potentially via corelease of glutamate from VTA cells; B. L. Lavin et al., 2005; Lewis \& O'Donnell, 2000). It was also argued that because $\mathrm{D}_{1}$ receptors are primarily expressed extrasynaptically (Smiley, Levey, Ciliax, \& Goldman-Rakic, 1994), they would not be sensitive to transient intrasynaptic DA signals and are therefore unable to support rapid updating (Lavin et al., 2005; Seamans \& Yang, 2004). In contrast, although $D_{2}$ receptors are 20 times less prevalent than $D_{1}$ receptors in PFC (Lidow, Goldman-Rakic, Gallager, \& Rakic, 1991), they may be located closer to the synapse and could therefore respond to high levels of phasic DA signals to drive updating (Lavin et al., 2005; Seamans \& Yang, 2004). This is consistent with recent observations that blockade of $\mathrm{PFC} \mathrm{D}_{2}$ receptors in primates impaired attentional set-shifting (requiring updating), with no effect on working memory maintenance (Floresco, Magyar, GhodsSharifi, Vexelman, \& Tse, 2006).

Thus, although we have focused our discussion on drug effects on $\mathrm{D}_{2}$ receptors within the $\mathrm{BG}$, we are certainly not suggesting that $\mathrm{D}_{2}$ receptors in PFC are functionally insignificant. Our argument is simply that the low doses of drugs used in this study acted primarily in the BG, and not the PFC, as discussed above. Nevertheless, some of our results may be consistent with a PFCdependent mechanism. For example, if the increase in DA by

\footnotetext{
${ }^{7}$ We note that if these $\mathrm{D}_{2}$-dependent effects in PFC played a substantial role in the present study, then we would have expected haloperidol to cause slowness of responding (by suppressing movement related frontal activity); this was not observed.
} 
haloperidol acting on presynaptic $\mathrm{D}_{2}$ receptors extended to the PFC, the Durstewitz and Seamans (2002) model predicts that the increased $D_{1}$ receptor stimulation would be associated with increased maintenance and stabilization of task-relevant information. This might also result in an inability to ignore this information once it becomes distracting (increased perseverative behavior), as was found in our study. Further, if the $\mathrm{D}_{2}$ stimulation by cabergoline extended to PFC, according to Seamans and Yang (2004), it would facilitate updating of working memory representations and therefore cause increased distractibility as was also observed. Finally, it is also possible that $D_{1}$ receptor function is affected in PFC indirectly by altering the balance of $D_{1}$ and $D_{2}$ receptor synergism (e.g., Clark \& White, 1987). Future research is therefore necessary to disentangle the potential roles for $D_{1} / D_{2}$ receptor drug effects in both BG and PFC in executive function tasks.

Nevertheless, we believe that the most parsimonious account of our data is a model that subsumes both lower level reinforcement learning and higher order cognitive effects. Thus, given the known role of the BG/DA system in reinforcement learning, and the converging results with Parkinson's disease patients (Frank et al., 2004), together with the arguments for preferential drug action in striatum described above, it should be relatively uncontroversial that the learning effects reported here stemmed from DA effects within the BG and these effects would be more difficult to explain with prefrontal mechanisms. This is further supported by our recent findings with the drug midazolam, which inactivates the PFC (and hippocampus) but leaves the striatum unaffected (e.g., Bagary et al., 2000; Reinsel et al., 2000). We found that whereas this drug profoundly impaired explicit memory processes, it spared probabilistic reinforcement learning (both positive and negative) and even enhanced some implicit forms of this learning (Frank, O'Reilly, \& Curran, in press). Given the growing evidence for BG/DA system implication in higher order cognitive function, it is likely that the same lower level drug effects in the BG affected working memory and attentional measures.

\section{Conclusions}

In summary, our results support a unified account of the role of DA in modulating cognitive processes that depends on the BG. Although this account is undoubtedly simplistic (i.e., it does not consider critical interactive effects between DA and other neurotransmitters), it has clear implications that may allow more indepth understanding of the neural bases for cognitive disorders in Parkinson's disease, ADHD, and schizophrenia. We offer the following cautious interpretation. In Parkinson's disease, low levels of both tonic and phasic DA are associated with diminished updating of PFC working memory representations and less overall frontal activity. In ADHD, low levels of tonic DA may actually result in enhanced DA release during bursting, as a result of less presynaptic feedback control (Grace, 2001; Seeman \& Madras, 2002). According to our framework, this hypersensitivity to phasic DA bursts would cause impulsive behavior and distractibility, because of a lack of control over BG Go signals. Finally, in schizophrenia, elevated levels of BG DA, combined with low levels of PFC DA (Seeman, 1987; Weinberger, 1987) may result in too low of a threshold for updating working memory representations, causing attention to inappropriate thoughts (see also Weiner $\&$ Joel, 2002) but less PFC maintenance of these representations.
Future research with behavioral paradigms such as those used in the present study may help to test these ideas.

\section{References}

Abi-Dargham, A., Rodenhiser, J., Printz, D., Zea-Ponce, Y., Gil, R., Kegeles, L. S., Weiss, R., Cooper, T. B., Mann, J. J., Van Heerturn, R. L., Gorman, J. M., \& Laruelle, M. (2000). Increased baseline occupancy of D2 receptors by dopamine in schizophrenia. Proceedings of the National Academy of Sciences, USA, 14, 8104-8109.

Alexander, G. E., DeLong, M. R., \& Strick, P. L. (1986). Parallel organization of functionally segregated circuits linking basal ganglia and cortex. Annual Review of Neuroscience, 9, 357-381.

Arnsten, A. F. (1997). Catecholamine regulation of the prefrontal cortex. Journal of Psychopharmacology, 11, 151-162.

Arnsten, A. F., Cai, J. X., Murphy, B. L., \& Goldman-Rakic, P. S. (1994). Dopamine D receptor mechanisms in the cognitive performance of young adult aged monkeys. Psychopharmacology, 116, 143-151.

Arnsten, A. F., Cai, J. X., Steere, J. C., \& Goldman-Rakic, P. S. (1995). Dopamine D receptor mechanisms contribute to age-related cognitive decline: The effects of quinpirole on memory and motor performance in monkeys. Journal of Neuroscience, 15, 3429-3439.

Aubert, I., Ghorayeb, I., Normand, E., \& Bloch, B. (2000). Phenotypical characterization of the neurons expressing the D1 and D2 dopamine receptors in the monkey striatum. Journal of Comparative Neurology, $418,22-32$.

Bagary, M., Fluck, E., File, S. E., Joyce, E., Lockwood, G., \& Grasby, P. (2000). Is benzodiazepene-induced amnesia due to deactivation of the left prefrontal cortex? Psychopharmacology, 150, 292-299.

Barch, D. M., Braver, T. S., Nystom, L. E., Forman, S. D., Noll, D. C., \& Cohen, J. D. (1997). Dissociating working memory from task difficulty in human prefrontal cortex. Neuropsychologia, 35, 1373-1380.

Barch, D. M., Carter, C. S., Braver, T. S., Sabb, F. W., MacDonald, A., Noll, D. C., \& Cohen, J. D. (2001). Selective deficits in prefrontal cortex function in medication-naive patients with schizophrenia. Archives of General Psychiatry, 58, 280-288.

Barrett, S. L., Bell, R., Watson, D., \& King, D. J. (2004). Effects of amisulpiride, risperidone and chlorpromazine on auditory and visual latent inhibition, prepulse inhibition, executive function and eye movements in healthy volunteers. Journal of Psychopharmacology, 18, 156172.

Basso, M. A., \& Wurtz, R. H. (2002). Neuronal activity in substantia nigra pars reticulata during target selection. Journal of Neuroscience, 22, $1883-1894$.

Bayer, H. M. (2004). A role for the substantia nigra in learning and motor control. Unpublished doctoral dissertation, New York University.

Bayer, H. M., \& Glimcher, P. W. (2005). Midbrain dopamine neurons encode a quantitative reward prediction error signal. Neuron, 47, 129141.

Beiser, D. G., \& Houk, J. C. (1998). Model of cortical-basal ganglionic processing: Encoding the serial order of sensory events. Journal of Neurophysiology, 79, 3168-3188.

Ben-Jonathan, N. (1985). Dopamine: A prolactin-inhibiting hormone. Endocrinological Review, 6, 564-589.

Bilder, R. M., Volavka, J., Lachman, H. M., \& Grace, A. A. (2004). The catechol-O-methyltransferase polymorphism: Relations to the tonicphasic dopamine hypothesis and neuropsychiatric phenotypes. Neuropsychopharmacology, 29, 1943-1961.

Biller, B. M., Molitch, M. E., Vance, M. L., Cannistraro, K. B., Davis, K. R., Simons, J., Schoenfelder, J. R., \& Klibanski, A. (1996). Treatment of prolactin-secreting macroadenomas with the once-weekly dopamine agonist cabergoline. Journal of Clinical Endocrinology \& Metabolism: Clinical and Experimental, 81, 2338-2343.

Black, K. J., Gado, M. H., \& Perlmutter, J. S. (1997). PET measurement of dopamine D2 receptor-mediated changes in striatopallidal function. Journal of Neuroscience, 17, 3168-3177. 
Bokura, H., Yamaguchi, S., \& Kobayashi, S. (2005). Event-related potentials for response inhibition in Parkinson's disease. Neuropsychologia, 43, 967-975.

Braver, T. S., Barch, D. M., Keys, B. A., Carter, C. S., Cohen, J. D., Kaye, J. A., Janowsky, J. S., Taylor, S. F., Yesavage, J. A., \& Mumenthaler, M. S. (2001). Context processing in older adults: Evidence for a theory relating cognitive control to neurobiology in healthy aging. Journal of Experimental Psychology: General, 130, 746-763.

Braver, T. S., \& Cohen, J. D. (2000). On the control of control: The role of dopamine in regulating prefrontal function and working memory. In S. Monsell \& J. Driver (Eds.), Control of cognitive processes: Attention and performance XVIII (pp. 713-737). Cambridge, MA: MIT Press.

Brown, J. W., Bullock, D., \& Grossberg, S. (2004). How laminar frontal cortex and basal ganglia circuits interact to control planned and reactive saccades. Neural Networks, 17, 471-510.

Brown, R. G., \& Marsden, C. D. (1990). Cognitive function in Parkinson's disease: From description to theory. Trends in Neurosciences, 13, 21-29.

Bymaster, F., Perry, K. W., Nelson, D. L., Wong, D. T., Rasmussen, K., Moore, N. A., \& Calligaro, D. O. (1999). Olanzapine: A basic science update. British Journal of Psychiatry, 37 (Suppl), 36-40.

Calabresi, P., Saiardi, A., Pisani, A., Baik, J. H., Centonze, D., Mercuri, N. B., Bernardi, G., \& Borrelli, E. (1997). Abnormal synaptic plasticity in the striatum of mice lacking dopamine D2 receptors. Journal of Neuroscience, 17, 4536-4544.

Camps, M., Cortes, R., Gueye, B., Probst, A., \& Palacios, J. M. (1989). Dopamine receptors in the human brain: Autoradiographic distribution of D sites. Neuroscience, 28, 275-290.

Centonze, D., Picconi, B., Gubellini, P., Bernardi, G., \& Calabresi, P. (2001). Dopaminergic control of synaptic plasticity in the dorsal striatum. European Journal of Neuroscience, 13, 1071-1077.

Centonze, D., Usiello, A., Costa, C., Picconi, B., Erbs, E., Bernardi, G., Borrelli, E., \& Calabresi, P. (2004). Chronic haloperidol promotes corticostriatal long-term potentiation by targeting dopamine D2L receptors. Journal of Neuroscience, 24, 8214-8222.

Charbonneau, D., Riopelle, R. J., \& Beninger, R. J. (1996). Impaired incentive learning in treated Parkinson's disease. Canadian Journal of Neurological Sciences, 23, 271-278.

Chen, Y. C., Choi, J. K., Andersen, S., Rosen, B. R., \& Jenkins, B. G. (2005). Mapping dopamine D2/D3 receptor function using pharmacological magnetic resonance imaging. Psychopharmacology (Berl), 180, $705-715$.

Clark, D., \& White, F. J. (1987). D1 dopamine receptor-the search for a function: A critical evaluation of the D1/D2 dopamine receptor classification and its functional implications. Synapse, 1, 347-388.

Cohen, J. D., Braver, T. S., \& Brown, J. W. (2002). Computational perspectives on dopamine function in prefrontal cortex. Current Opinion in Neurobiology, 12, 223-229.

Colao, A., Lombardi, G., \& Annunziato, L. (2000). Cabergoline. Expert Opinion on Pharmacotherapy, 1, 555-574.

Collins, P., Wilkinson, L. S., Everitt, B. J., Robbins, T. W., \& Roberts, A. C. (2000). The effect of dopamine depletion from the caudate nucleus of the common marmoset (callithrix jacchus) on tests of prefrontal cognitive function. Behavioral Neuroscience, 114, 3-17.

Cools, R. (2005). Dopaminergic modulation of cognitive function-Implications for L-DOPA treatment in Parkinson's disease. Neuroscience and Biobehavioral Reviews, 1-23.

Cools, R., Barker, R. A., Sahakian, B. J., \& Robbins, T. W. (2001). Enhanced or impaired cognitive function in Parkinson's disease as a function of dopaminergic medication and task demands. Cerebral Cortex, 11, 1136-1143.

Cools, R., Barker, R. A., Sahakian, B. J., \& Robbins, T. W. (2003). L-Dopa medication remediates cognitive inflexibility, but increases impulsivity in patients with Parkinson's disease. Neuropsychologia, 41, 1431-1441.

Cools, R., Lewis, S., Clark, L., Barker, R., \& Robbins, T. W. (2005, April). L-DOPA in Parkinson's disease abolishes nucleus accumbens activation during probabilistic reversal learning. Paper presented at the annual meeting of the Cognitive Neuroscience Society, New York.

Corsello, S. M., Ubertini, G., Altomare, M., Lovicu, R. M., Migneco, M. G., Rota, C. A., \& Colosimo, C. (2003). Giant prolactinomas in men: Efficacy of cabergoline treatment. Clinical Endocrinology, 58, 662-670.

Cragg, S. J., Hille, C. J., \& Greenfield, S. A. (2002). Functional domains in dorsal striatum of the nonhuman primate are defined by the dynamic behavior of dopamine. Journal of Neuroscience, 22, 5705-5712.

Creese, I., Sibley, D. R., Hamblin, M. W., \& Leff, S. E. (1983). The classification of dopamine receptors: Relationship to radioligand binding. Annual Review of Neuroscience, 6, 43-71.

Crofts, H. S., Dalley, J. W., Collins, P., Van Denderen, J. C., Everitt, B. J., Robbins, T. W., \& Roberts, A. C. (2001). Differential effects of 6-OHDA lesions of the frontal cortex and caudate nucleus on the ability to acquire an attentional set. Cerebral Cortex, 11, 1015-1026.

Czernecki, V., Pillon, B., Houeto, J. L., Pochon, J. B., Levy, R., \& Dubois, B. (2002). Motivation, reward, and Parkinson's disease: Influence of dopatherapy. Neuropsychologia, 40, 2257-2267.

Daneman, M., \& Carpenter, P. A. (1980). Individual differences in working memory and reading. Journal of Verbal Learning and Verbal Behavior, 19, 450-466.

Daw, N. D., Kakade, S., \& Dayan, P. (2002). Opponent interactions between serotonin and dopamine. Neural Networks, 15, 603-616.

Delgado, M. R., Nystrom, L. E., \& Fiez, J. A. (2000). Tracking the hemodynamic responses to reward and punishment in the striatum. Journal of Neurophysiology, 84, 3072.

Dellu-Hagedorn, F. (2005). Spontaneous individual differences in cognitive performances of young adult rats predict locomotor response to amphetamine. Neurobiology of Learning and Memory, 83, 43-47.

Dougherty, D. D., Bonab, A. A., Spencer, T. J., Rauch, S. L., Madras, B. K., \& Fischman, A. J. (1999). Dopamine transporter density in patients with attention deficit hyperactivity disorder. The Lancet, 354, 2132-2133.

Dreher, J. C., \& Burnod, Y. (2002). An integrative theory of the phasic and tonic modes of dopamine modulation in the prefrontal cortex. Neural Networks, 15, 583-602.

Durstewitz, D., \& Seamans, J. K. (2002). The computational role of dopamine D1 receptors in working memory. Neural Networks, 15, $561-572$.

Durstewitz, D., Seamans, J. K., \& Sejnowski, T. J. (2000). Dopaminemediated stabilization of delay-period activity in a network model of prefrontal cortex. Journal of Neurophysiology, 83, 1733-1750.

Eyny, Y. S., \& Horvitz, J. C. (2003). Opposing roles of D1 and D2 receptors in appetitive conditioning. Journal of Neuroscience, 23, 1584-1587.

Fallon, J. H., \& Moore, R. Y. (1978). Catecholamine innervation of the basal forebrain: IV. Topography of the dopamine projection to the basal forebrain and neostriatum. Journal of Comparative Neurology, 180, $545-580$.

Finch, D. M. (1999). Plasticity of responses to synaptic inputs in rat ventral striatal neurons after repeated administration of the dopamine D2 antagonist raclopride. Synapse, 31, 297-301.

Floresco, S. B., Magyar, O., Ghods-Sharifi, S., Vexelman, C., \& Tse, M. T. (2006). Multiple dopamine receptor subtypes in the medial prefrontal cortex of the rat regulate set-shifting. Neuropsychopharmacology, 31, 297-309.

Fog, R. (1972). On stereotypy and catalepsy: Studies on the effect of amphetamines and neuroleptics in rats. Acta Neurologica Scandinavica, 50 (Suppl.), 3-66.

Frank, M. J. (2005). Dynamic dopamine modulation in the basal ganglia: A neurocomputational account of cognitive deficits in medicated and non-medicated Parkinsonism. Journal of Cognitive Neuroscience, 17, $51-72$.

Frank, M. J. (in press). Hold your horses: A dynamic computational role for the subthalamic nucleus in decision making. Neural Networks.

Frank, M. J., \& Claus, E. D. (in press). Anatomy of a decision: Striato- 
orbitofrontal interactions in reinforcement learning, decision making and reversal. Psychological Review.

Frank, M. J., Loughry, B., \& O'Reilly, R. C. (2001). Interactions between the frontal cortex and basal ganglia in working memory: A computational model. Cognitive, Affective, and Behavioral Neuroscience, 1, 137-160.

Frank, M. J., O'Reilly, R. C., \& Curran, T. (in press). When memory fails, intuition reigns: Midazolam enhances implicit inference in humans. Psychological Science.

Frank, M. J., Seeberger, L. C., \& O'Reilly, R. C. (2004). By carrot or by stick: Cognitive reinforcement learning in Parkinsonism. Science, 306, 1940-1943.

Frank, M. J., Woroch, B. S., \& Curran, T. (2005). Error-related negativity predicts reinforcement learning and conflict biases. Neuron, 47, 495-501.

Garris, P. A., Budygin, E. A., Phillips, P. E., Venton, B. J., Robinson, D. L., Bergstrom, B. P., Rebec, G. V., \& Wightman, R. M. (2003). A role for presynaptic mechanisms in the actions of nomifensine and haloperidol. Neuroscience, 118, 819-829.

Gerfen, C. R. (1992). The neostriatal mosaic: Multiple levels of compartmental organization in the basal ganglia. Annual Review of Neuroscience, 15, 285-320.

Gibbs, S. E. B., \& D'Esposito, M. (2005). Individual capacity differences predict working memory performance and prefrontal activity following dopamine receptor stimulation. Cognitive, Affective, and Behavioral Neuroscience, 5, 212-221.

Gonon, F. J. (1997). Prolonged and extrasynaptic excitatory action of dopamine mediated by D1 receptors in the rat striatum in vivo. Journal of Neuroscience, 17, 5972-5978.

Goto, Y., \& Grace, A. A. (2005). Dopaminergic modulation of limbic and cortical drive of nucleus accumbens in goal-directed behavior. Nature Neuroscience, 8, 805-812.

Grace, A. A. (1991). Phasic versus tonic dopamine release and the modulation of dopamine system responsivity: A hypothesis for the etiology of schizophrenia. Neuroscience, 41, 1-24.

Grace, A. A. (1995). The tonic/phasic model of dopamine system regulation: Its relevance for understanding how stimulant abuse can alter basal ganglia function. Drug and Alcohol Dependence, 37, 111-129.

Grace, A. A. (2001). Psychostimulant actions on dopamine and limbic system function: Relevance to the pathophysiology and treatment of ADHD. In M. V. Solanto, \& A. F. Arnsten (Eds.), Stimulant drugs and ADHD: Basic and clinical neuroscience (pp. 134-155). New York: Oxford University Press.

Gray, N. S., Pickering, A. D., Hemsley, D. R., Dawling, S., \& Gray, J. A. (1992). Abolition of latent inhibition by a single 5-mg dose of d-amphetamine in man. Psychopharmacology, 107, 425-430.

Gurney, K., Prescott, T. J., \& Redgrave, P. (2001). A computational model of action selection in the basal ganglia: I. A new functional anatomy. Biological Cybernetics, 84, 401-410.

Harden, D. G., \& Grace, A. A. (1995). Activation of dopamine cell firing by repeated L-DOPA administration to dopamine-depleted rats: Its potential role in mediating the therapeutic response to L-DOPA treatment. Journal of Neuroscience, 15, 6157-6166.

Hazy, T. E., Frank, M. J., \& O'Reilly, R. C. (in press). Banishing the homunculus: Making working memory work. Neuroscience.

Hernandez-Lopez, S., Bargas, J., Surmeier, D. J., Reyes, A., \& Galarraga, E. (1997). D1 receptor activation enhances evoked discharge in neostriatal medium spiny neurons by modulating an L-type Ca conductance. Journal of Neuroscience, 17, 3334-3342.

Hernandez-Lopez, S., Tkatch, T., Perez-Garci, E., Galarraga, E., Bargas, J., Hamm, H., \& Surmeier, D. J. (2000). D2 dopamine receptors in striatal medium spiny neurons reduce L-type Ca currents and excitability via a novel PLC $\beta 1$-IP-calcineurin-signaling cascade. Journal of Neuroscience, 20, 8987-8995.

Hikosaka, O. (1994). Role of basal ganglia in control of innate movements, learned behaviour and cognition. In G. Percheron, J. McKenzie, \& J.
Feger (Eds.), The basal ganglia: IV. New ideas and data on structure and function (pp. 598-696). New York: Plenum Press.

Holroyd, C. B., \& Coles, M. G. H. (2002). The neural basis of human error processing: Reinforcement learning, dopamine, and the error-related negativity. Psychological Review, 109, 679-709.

Honey, G. D., Suckling, J., Zelaya, F., Long, C., Routledge, C., Jackson, S., Ng, V., Fletcher, P. C., Williams, S. C. R., Brown, J., \& Bullmore, E. T. (2003). Dopaminergic drug effects on physiological connectivity in a human cortico-striato-thalamic system. Brain: A Journal of Neurology, 126, 1767-1781.

Ichikawa, K., \& Kojima, M. (2001). Pharmacological effects of cabergoline against Parkinsonism. Nippon Yakurigaku Zasshi, 117, 395-400.

Ichise, M., Kim, Y. J., Ballinger, J. R., Vines, D., Erami, S. S., Tanaka, F., \& Lang, A. E. (1999). SPECT imaging of pre- and postsynaptic dopaminergic alterations in L-dopa-untreated PD. Neurology, 52, 1206-1214.

Ilgin, N., Senol, S., Gucuyener, K., Gokcora, N., Atavci, S., \& Sener, S. (2001). Is increased D2 receptor availability associated with response to stimulant medication in ADHD. Developmental Medicine and Child Neurology, 43, 755-760.

Jiang, H., Stein, B. E., \& McHaffie, J. G. (2003). Opposing basal ganglia processes shape midbrain visuomotor activity bilaterally. Nature, 419 , 982-985.

Joel, D., \& Weiner, I. (1999). Striatal contention scheduling and the split circuit scheme of basal ganglia-thalamocortical circuitry: From anatomy to behaviour. In R. Miller \& J. R. Wickens (Eds.), Conceptual advances in brain research: Brain dynamics and the striatal complex (pp. 209236). Amsterdam: Harwood Academic.

Joel, D., \& Weiner, I. (2000). The connections of the dopaminergic system with the striatum in rats and primates: An analysis with respect to the functional and compartmental organization of the striatum. Neuroscience, 96, 451-474.

Kapur, S., Remington, G., Jones, C., Wilson, A., DaSilva, J., Houle, S., \& Zipursky, R. B. (1996). High levels of dopamine D receptor occupancy with low-dose haloperidol treatment: A PET study. American Journal of Psychiatry, 153, 948-950.

Kimberg, D. Y., D'Esposito, M., \& Farah, M. J. (1997). Effects of bromocriptine on human subjects depend on working memory capacity. Neuroreport, 8, 3581-3585.

Kish, S. J., Shannak, K., \& Hornykiewicz, O. (1988). Uneven pattern of dopamine loss in the striatum of patients with idiopathic Parkinson's disease. New England Journal of Medicine, 318, 876-880.

Kumari, V., Corr, P. J., Mulligan, O. F., Cotter, P. A., Checkley, S. A., \& Gray, J. A. (1997). Effects of acute administration of $d$-amphetamine and haloperidol on procedural learning in man. Psychopharmacology, 129, 271-276.

Kuroki, T., Meltzer, H. Y., \& Ichikawa, J. (1999). Effects of antipsychotic drugs on extracellular dopamine levels in rat medial prefrontal cortex and nucleus accumbens. Journal of Pharmacology and Experimental Therapeutics, 288, 774-781.

Lavin, A., Nogueira, L., Lapish, C. C., Wightman, R. M., Phillips, P. E. M., \& Seamans, J. K. (2005). Mesocortical dopamine neurons operate in distinct temporal domains using multimodal signaling. Journal of Neuroscience, 25, 5013-5023.

Lewis, B. L., \& O'Donnell, P. (2000). Ventral tegmental area afferents to the prefrontal cortex maintain membrane potential "up" states in pyramidal neurons via D1 dopamine receptors. Cerebral Cortex, 10, 1168-1175.

Lewis, S. J., Dove, A., Robbins, T. W., Barker, R. A., \& Owen, A. M. (2004). Striatal contributions to working memory: A functional magnetic resonance imaging study in humans. European Journal of Neuroscience, 19, 755-760.

Lidow, M. S., Goldman-Rakic, P. S., Gallager, D. W., \& Rakic, P. (1991). Distribution of dopaminergic receptors in the primate cerebral cortex: Quantitative autoradiographic analysis using $[\mathrm{H}]$ raclopride, $[\mathrm{H}]$ spiperone and $[\mathrm{H}] \mathrm{SCH} 23390$. Journal of Neuroscience, 40, 657-671.

Luciana, M., Hanson, H. L., \& Whitley, C. B. (2004). A preliminary report 
on dopamine system reactivity in PKU: Acute effects of haloperidol on neuropsychological, physiological, and neuroendocrine functions. Psychopharmacology, 175, 18-25.

Mahon, S., Casassus, G., Mulle, C., \& Charpier, S. (2003). Spikedependent intrinsic plasticity increases firing probability in rat striatal neurons in vivo. Journal of Physiology, 550, 947-959.

Mark, K. A., Soghomonian, J. J., \& Yamamoto, B. K. (2004). High-dose methamphetamine acutely activates the striatonigral pathway to increase striatal glutamate and mediate long-term dopamine toxicity. Journal of Neuroscience, 24, 11449-11456.

Mattay, V. S., Callicott, J. H., Bertolino, A., Heaton, I., Frank, J. A., Coppola, R., Berman, K. F., Goldberg, T. E., \& Weinberger, D. R. (2000). Effects of dextroamphetamine on cognitive performance and cortical activation. Neuroimage, 12, 268-275.

McGowan, S., Lawrence, A. D., Sales, T., Quested, D., \& Graby, P. (2004). Presynaptic dopamine dysfunction in schizophrenia: A positron emission tomographic [18f]fluorodopa study. Archives of General Psychiatry, 61, 134-142.

Mehta, M. A., Hinton, E. C., Montgomery, A. J., Bantick, R. A., \& Grasby, P. M. (2005). Sulpiride and mnemonic function: Effects of a dopamine D2 receptor antagonist on working memory, emotional memory and long-term memory in healthy volunteers. Journal of Psychopharmacology, 19, 29-38.

Mehta, M. A., Manes, F. F., Magnolfi, G., Sahakian, B. J., \& Robbins, T. W. (2004). Impaired set-shifting and dissociable effects on tests of spatial working memory following the dopamine D2 receptor antagonist sulpiride in human volunteers. Psychopharmacology (Berl), 176, 331-342.

Mehta, M. A., McGowan, S. W., Lawrence, A. D., Aitken, M. R. F., Montgomery, A. J., \& Grasby, P. M. (2003). Systemic sulpiride modulates striatal blood flow: Relationships to spatial working memory and planning. Neuroimage, 20, 1982-1994.

Mehta, M. A., Sahakian, B. J., McKenna, P. J., \& Robbins, T. W. (1999). Systemic sulpiride in young adults simulates the profile of cognitive deficits in Parkinson's disease. Psychopharmacology, 146, 162-174.

Mehta, M. A., Swainson, R., Ogilvie, A. D., Sahakian, B. J., \& Robbins, T. W. (2001). Improved short-term spatial memory but impaired reversal learning following the dopamine D2 agonist bromocriptine in human volunteers. Psychopharmacology, 159, 10-20.

Mink, J. W. (1996). The basal ganglia: Focused selection and inhibition of competing motor programs. Progress in Neurobiology, 50, 381-425.

Moghaddam, B., \& Bunney, B. S. (1990). Acute effects of typical and atypical antipsychotic drugs on the release of dopamine from prefrontal cortex, nucleus accumbens, and striatum in the rat: An in vivo microdialysis study. Journal of Neurochemistry, 54, 1755-1760.

Muller, U., von Cramon, D. Y., \& Pollman, S. (1998). D1- versus D2receptor modulation of visuospatial working memory in humans. Journal of Neuroscience, 18, 2720-2728.

Nieoullon, A. (2002). Dopamine and the regulation of cognition and attention. Progress in Neurobiology, 67, 53-83.

Nilsson, C. L., Ekman, A., Hellstrand, M., \& Eriksson, E. (1996). Inverse agonism at dopamine $\mathrm{D}_{2}$ receptors. Haloperidol-induced prolactin release from $\mathrm{GH} 4 \mathrm{C} 1$ cells transfected with the human $\mathrm{D}_{2}$ receptor is antagonized by $\mathrm{R}(-)-\mathrm{n}$-propylnorapomorphine, raclopride, and phenoxybenzamine. Neuropsychopharmacology, 15, 53-61.

Nishi, A., Snyder, G. L., \& Greengard, P. (1997). Bidirectional regulation of DARPP-32 phosphorylation by dopamine. Journal of Neuroscience, $17,8147-8155$.

O’Reilly, R. C., \& Frank, M. J. (2006). Making working memory work: A computational model of learning in the prefrontal cortex and basal ganglia. Neural Computation, 18, 283-328.

Owen, A. M., Doyon, J., Dagher, A., Sadikot, A., \& Evans, A. C. (1998). Abnormal basal ganglia outflow in Parkinson's disease identified with PET: Implications for higher cortical functions. Brain, 121, 949-965.

Owen, A. M., Roberts, A. C., Hodges, J. R., Summers, B. A., Polkey, C. E., \& Robbins, T. W. (1993). Contrasting mechanisms of impaired atten- tional set-shifting in patients with frontal lobe damage or Parkinson's disease. Brain, 116, 1159-1175.

Parent, A., \& Hazrati, L. (1995). Functional anatomy of the basal ganglia: II. The place of subthalamic nucleus and external pallidum in basal ganglia circuitry. Brain Research Reviews, 20, 128-154.

Pehek, E. A. (1999). Comparison of effects of haloperidol administration on amphetamine-stimulated dopamine release in the rat medial prefrontal cortex and dorsal striatum. Journal of Pharmacology and Experimental Therapeutics, 289, 14-23.

Peretti, C. S., Danion, J. M., Kauffmann-Muller, F., Grangé, D., Patat, A., \& Rosenzweig, P. (1997). Effects of haloperidol and amisulpiride on motor and cognitive skill learning in healthy volunteers. Psychopharmacology, 131, 329-338.

Perlstein, W. M., Dixit, N. K., Carter, C. S., Noll, D. C., \& Cohen, J. D. (2003). Prefrontal cortex dysfunction mediates deficits in working memory and prepotent responding in schizophrenia. Biological Psychiatry, $53,25-38$

Phillips, A. G., Ahn, S., \& Floresco, S. B. (2004). Magnitude of dopamine release in medial prefrontal cortex predicts accuracy of memory on a delayed response task. Journal of Neuroscience, 24, 547-553.

Pothos, E. N., Davila, V., \& Sulzer, D. (1998). Presynaptic recording of quanta from midbrain dopamine neurons and modulation of the quantal size. Journal of Neuroscience, 18, 4106-4118.

Radnikow, G., \& Misgeld, U. (1998). Dopamine D1 receptors facilitate GABAA synaptic currents in the rat substantia nigra pars reticulata. Journal of Neuroscience, 18(6), 2009-2016.

Redgrave, P., Prescott, T. J., \& Gurney, K. (1999a). Is the short-latency dopamine response too short to signal reward error? Trends in Neurosciences, 22, 146-151.

Redgrave, P., Prescott, T. J., \& Gurney, K. (1999b). The basal ganglia: A vertebrate solution to the selection problem? Neuroscience, 89, 1009-1023.

Reinsel, R. A., Veselis, R. A., Dnistrian, A. M., Feshchenko, V. A., Beattle, B. J., \& Duff, M. R. (2000). Midazolam decreases cerebral blood flow in the left prefrontal cortex in a dose-dependent fashion. The International Journal of Neuropsychopharmacology, 3, 117-127.

Richfield, E. K., Penney, J. B., \& Young, A. B. (1989). Anatomical and affinity state comparisons between dopamine D1 and D2 receptors in the rat central nervous system. Neuroscience, 30, 767-777.

Ridley, R. M., Haystead, T. A., \& Baker, H. F. (1981). An analysis of visual object reversal learning in the marmoset after amphetamine and haloperidol. Pharmacology, Biochemistry and Behavior, 14, 345-351.

Rinne, J. O., Portin, R., Ruottinen, H., Nurmi, E., Bergman, J., Haaparanta, M., \& Solin, O. (2000). Cognitive impairment and the brain dopaminergic system in Parkinson's disease: (F)-fluorodopa positron emission tomographic study. Archives of Neurology, 57, 470-475.

Rinne, U. K., Laihinen, A., Rinne, J. O., Nagren, K., Bergman, J., \& Ruotsalainen, U. (1990). Positron emission tomography demonstrates dopamine D2 receptor supersensitivity in the striatum of patients with early Parkinson's disease. Movement Disorders, 5, 55-59.

Robertson, G. S., Vincent, S. R., \& Fibiger, H. C. (1992). $D_{1}$ and $D_{2}$ dopamine receptors differentially regulate c-fos expression in striatonigral and striatopallidal neurons. Neuroscience, 49, 285-296.

Roesch-Ely, D., Scheffel, H., Weiland, S., Schwaninger, M., Hundemer, H-P., Kolter, T., \& Weisbrod, M. (2005). Differential dopaminergic modulation of executive control in healthy subjects. Psychopharmacol$\operatorname{ogy}($ Berl), 178, 420-430.

Roitman, M. R., Philips, P. E., Stuber, G., Wightman, R. M., \& Carelli, R. M. (2004). Dopamine operates as a subsecond modulator of food seeking. Journal of Neuroscience, 24, 1265-1271.

Rougier, N. P., \& O'Reilly, R. C. (2002). Learning representations in a gated prefrontal cortex model of dynamic task switching. Cognitive Science, 26, 503-520.

Sanberg, P. R. (1980). Haloperidol-induced catalepsy is mediated by postsynaptic dopamine receptors. Nature, 284, 472-473.

Satoh, T., Nakai, S., Sato, T., \& Kimura, M. (2003). Correlated coding of 
motivation and outcome of decision by dopamine neurons. Journal of Neuroscience, 23, 9913-9923.

Sawaguchi, T. (2001). The effects of dopamine and its antagonists on directional delay-period activity of prefrontal neurons in monkeys during an oculomotor delayed-response task. Neuroscience Research, 41, $115-128$.

Sawaguchi, T., \& Goldman-Rakic, P. S. (1991). D1 dopamine receptors in prefrontal cortex: Involvement in working memory. Science, 251, 947-950.

Schmitz, Y., Benoit-Marand, M., Gonon, F., \& Sulzer, D. (2003). Presynaptic regulation of dopaminergic neurotransmission. Journal of Neurochemistry, 87, 273-289.

Schoemaker, H., Claustre, Y., Fage, D., Rouquier, L., Chergui, K., Curet, O., Oblin, A., Gonon, F., Carter, C., Benavides, J., \& Scatton, B. (1997). Neurochemical characteristics of amisulpiride, an atypical dopamine D2/D3 receptor antagonist with both presynaptic and limbic selectivity. Journal of Pharmacology and Experimental Therapeutics, 280, 83-97.

Schultz, W. (1998). Predictive reward signal of dopamine neurons. Journal of Neurophysiology, 80, 1-27.

Schultz, W. (2002). Getting formal with dopamine and reward. Neuron, 36, 241-263.

Schultz, W., Dayan, P., \& Montague, P. R. (1997). A neural substrate of prediction and reward. Science, 275, 1593-1599.

Seamans, J. K., Gorelova, N., Durstewitz, D., \& Yang, C. R. (2001). Bidirectional dopamine modulation of gabaergic inhibition in prefrontal cortical pyramidal neurons. Journal of Neuroscience, 21, 3628-3638.

Seamans, J. K., \& Yang, C. R. (2004). The principal features and mechanisms of dopamine modulation in the prefrontal cortex. Progress in Neurobiology, 74, 1-57.

Seeman, P. (1987). Dopamine receptors and the dopamine hypothesis of schizophrenia. Synapse, 1, 133-152.

Seeman, P., \& Kapur, S. (2000). Schizophrenia: More dopamine, more D2 receptors. Proceedings of the National Academy of Sciences, USA, 97, 7673.

Seeman, P., \& Madras, B. (2002). Methylphenidate elevates resting dopamine, which lowers the impulse-triggered release of dopamine: A hypothesis. Behavioural Brain Research, 130, 79-83.

Servan-Schreiber, D., Cohen, J. D., \& Steingard, S. (1997). Schizophrenic deficits in the processing of context: A test of a theoretical model. Archives of General Psychiatry, 53, 1105-1113.

Servan-Schreiber, D., Printz, H., \& Cohen, J. D. (1990). A network model of catecholamine effects: Gain, signal-to-noise ratio, and behavior. Science, 249, 892-895.

Sesack, S. R., Hawrylak, V. A., Matus, C., Guido, M. A., \& Levey, A. I. (1998). Dopamine axon varicosities in the prelimbic division of the rat prefrontal cortex exhibit sparse immunoreactivity for the dopamine transporter. Journal of Neuroscience, 18, 2697-2708.

Shohamy, D., Myers, C. E., Geghman, K. D., Sage, J., \& Gluck, M. A. (in press). L-Dopa impairs learning, but spares generalization, in Parkinson's disease. Neuropsychologia, 44, 774-784.

Shohamy, D., Myers, C. E., Grossman, S., Sage, J., \& Gluck, M. A. (2005). The role of dopamine in cognitive sequence learning: Evidence from Parkinson's disease. Behavioural Brain Research, 156, 191-199.

Smiley, J. F., Levey, A. I., Ciliax, B. J., \& Goldman-Rakic, P. S. (1994). D1 dopamine receptor immunoreactivity in human and monkey cerebral cortex: Predominant and extrasynaptic localization in dendritic spines. Proceedings of the National Academy of Sciences, USA, 91, 5720-5724.

Smith, A. G., Neill, J. C., \& Costall, B. (1999). The D3/D2 receptor agonist 7-OH-DPAT induces cognitive impairment in the marmoset. Pharmacology, Biochemistry and Behavior, 63, 201-211.

Smith, J. K., Neill, J. C., \& Costall, B. (1997). Bidirectional effects of dopamine D2 receptor antagonists on responding for a conditioned reinforcer. Pharmacology, Biochemistry and Behavior, 57, 843-849.

Starke, K., Gothert, M., \& Kilbinger, H. (1989). Modulation of neurotransmitter release by presynaptic autoreceptors. Physiology Reviews, 69, 864-989.
Stocchi, F., Vacca, L., Berardelli, A., Onofrj, M., Manfredi, M., \& Ruggieri, S. (2003). Dual dopamine agonist treatment in Parkinson's disease. Journal of Neurology, 250, 822-826.

Swainson, R., Rogers, R. D., Sahakian, B. J., Summers, B. A., Polkey, C. E., \& Robbins, T. W. (2000). Probabilistic learning and reversal deficits in patients with Parkinson's disease or frontal or temporal lobe lesions: Possible adverse effects of dopaminergic medication. Neuropsychologia, 38, 596-612.

Tanaka, S. (2002). Dopamine controls fundamental cognitive operations of multi-target spatial working memory. Neural Networks, 15, 573-582.

Trantham-Davidson, H., Neely, L. C., Lavin, A., \& Seamans, J. K. (2004). Mechanisms underlying differential D1 versus D2 dopamine receptor regulation of inhibition in prefrontal cortex. Journal of Neuroscience, $24,10652-10678$

Uziello, A., Baik, J. H., Rouge-Pont, F., Picetti, R., Dierich, A., Lemeur, M., Piazza, P. V., \& Borrelli, E. (2000). Distinct functions of the two isoforms of dopamine D2 receptors. Nature, 408, 199-203.

Wang, M., Vijayraghavan, S., \& Goldman-Rakic, P. S. (2004). Selective D2 receptor actions on the functional circuitry of working memory. Science, 303, 853-856.

Webster, J. E. A. (1994). Comparison of cabergoline and bromocriptine in the treatment of hyperprolactinemic amenorrhea. New England Journal of Medicine, 31, 904-909.

Weinberger, D. R. (1987). Implications of normal brain development for the pathogenesis of schizophrenia. Archives of General Psychiatry, 44, $660-669$.

Weiner, I., \& Joel, D. (2002). Dopamine in schizophrenia: Dysfunctional processing in basal ganglia-Thalamocortical split circuits. In G. Di Chiara (Ed.), Handbook of experimental pharmacology: Dopamine in the CNS (pp. 417-471). Berlin: Springer-Verlag.

Westerink, B. H. C. (2002). Can antipsychotic drugs be classified by their effects on a particular group of dopamine neurons in the brain? European Journal of Pharmacology, 455, 1-18.

Wickens, J. (1997). Basal ganglia: Structure and computations. Network: Computation in Neural Systems, 8, R77-R109.

Willcutt, E. G., Brodsky, K., Chhabildas, N., Shanahan, M., Yerys, B., Scott, A., \& Pennington, B. (2005). The neuropsychology of ADHD: Validity of the executive function hypothesis. In D. Gozal \& D. Molfese (Eds.), Attention deficit hyperactivity disorder: From genes to animal models to patients (pp. 185-214). Totowa, NJ: Humana Press.

Williams, G. V., \& Goldman-Rakic, P. S. (1995). Modulation of memory fields by dopamine D1 receptors in prefrontal cortex. Nature, 376, 572-575.

Wu, Q., Reith, M. E., Walker, Q. D., Kuhn, C. M., Caroll, F. I., \& Garris, P. A. (2002). Concurrent autoreceptor-mediated control of dopamine release and uptake during neurotransmission: An in vivo voltammetric study. Journal of Neuroscience, 22, 6272-6281.

Yang, C. R., \& Seamans, J. K. (1996). Dopamine D1 receptor actions in layer V-VI rat prefrontal cortex neurons in vitro: Modulation of dendritic-somatic signal integration. Journal of Neuroscience, 16, 1922-1935.

Zald, D. H., Boileau, I., El-Dearedy, W., Gunn, R., McGlone, F., Dichter, G. S., \& Dagher, A. (2004). Dopamine transmission in the human striatum during monetary reward tasks. Journal of Neuroscience, 24 4105-4112.

Zhang, K., Grady, C. J., Tsapakis, E. M., Andersen, S. L., Tarazi, F. I., \& Baldessarini, R. J. (2004). Regulation of working memory by dopamine D4 receptor in rats. Neuropsychopharmacology, 29, 1648-1655.

Zhen, X., Torres, C., Cai, G., \& Friedman, E. (2002). Inhibition of protein tyrosine/mitogen-activated protein kinase phosphatase activity is associated with D2 dopamine receptor supersensitivity in a rat model of Parkinson's disease. Molecular Pharmacology, 62, 1356-1363.

Received October 31, 2005

Revision received January 23, 2006 Accepted January 26, 2006 